UC-33A

Issued: March 1987

LA--10872-MS

DE87 006309

\title{
General-Purpose Heat Source Safety Verification Test Program: Edge-On Flyer Plate Tests
}

\author{
T. G. George
}

DISCLAIMER

This report was prepared as an account of work sponsored by an agency of the L'nited States Government. Neither the United States Government nor any agency thereof, nor any of their employees, makes any warranty, express or implied, or assumes any legal liability or responsibility for the accuracy, completeness, or usefulness of any information, apparatus, product, or process disclosed, or represents that its use would not infringe privately owned rights. Reference herein to any specific commercial product, process, or service by trade name, trademark, manufacturer, or otherwise does not necessarily constitute or imply its endorsement, recommendation, or favoring by the United States Government or any agency thereof. The views and opinions of authors expressed herein do not necessarily state or reflect those of the Linited States Government or any agency thereof.

\section{MASTER}

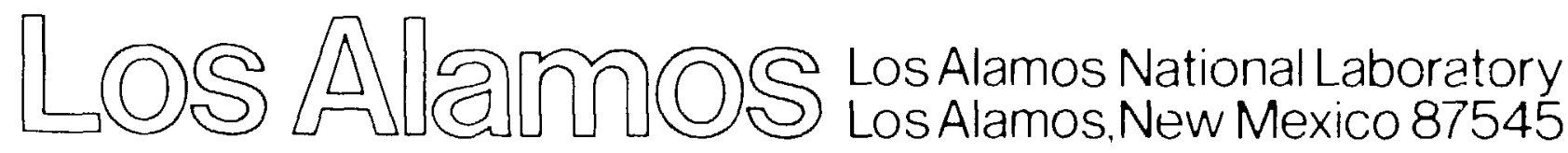




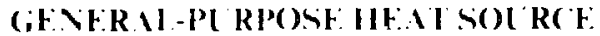 \\ SAFEIT VERIFIC AION IESI PROGRAM:

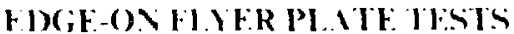

b!

I. (;. Cienge

\begin{abstract}
IBSTRAC"I
Ihe radiosotope thermoelectric generator (RIG) that will supply power for the Gatileo and I lisses space missions contains 18 General-Purpose Heat Source (GPHS) modules. The GPHS nodules provide power by transmitting the heat of ${ }^{2.38} \mathrm{Pu} \alpha$-decay to an array of thermoelectric elements. Fach module cuntains four ${ }^{2.38} \mathrm{PuO}_{2}$-fueled clads and generates 250 $\mathrm{W}(\mathrm{t})$. Because the possibility of a launch vehicle exp'osion always exists, and because such an explosion could generate a field of high-energy fragments, the fueled elads within each GPHS module must survive fragment impact. The edge-on flyer plate tests were included in the Safety lerification Test series to provide information on the mudule/clad response to the impact of high-energy plate fragments. The test results indicate that the edge-on impact of a 3.2-mm-thick, aluminum-alloy (2219-787) plate traveling at $915 \mathrm{~m} / \mathrm{s}$ causes the complete release of fuel from capsules contained within a bare GPIS module, and that the threshold velocity sufficient to cause the breach of a bare. simulant-fueled clad impacted by a $3.5-\mathrm{mm}$-thick. aluminum-allo! (5052-10) plate is approsimately $140 \mathrm{~m} / \mathrm{s}$.
\end{abstract}

\section{INTRODLC (TIO)}

The Gineral-Purpene Heat Surce (ciPHS) w a medular cornponent of the radiocisotope thermodectric generator (RTCi) that will proude pouce for a number of space missions. The first wo uses will be the VtSt Galileo and ESt L lysses formerly International SolarPolar) missions. The RT(igenerates electrical power by using the heat of ${ }^{38} \mathrm{Pu}$ (1-decal to create a temperature differential across a thermoclectric array. The (ialileo mission will require tuo RT(is and lysses will use a single RTC;. Each RTCicontame 18 ciPHS modules.

Each fully loaded cipls moduk contains four ${ }^{238} \mathrm{PuO}_{2}$-fueled clads and prorktes a tontal thermal nutput of $250 \mathrm{~W}$. Fach fucled chad tor capsule consists of at ${ }^{238} \mathrm{PuO}_{2}$ fuel pellet encapsulated wathon an iridiun?-illos (DOP-26) shell. Fwo fucked dads are hald whine a Fineweave-Pierced Fatre* if WPly graphile impace

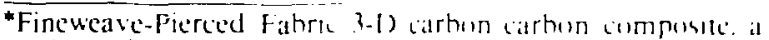
product of AV(r) Sistems 1) whan. InI I wall si. Wilminglon. MA 1188 ? shell (GIS). and two GiSs are contained within the FW PF acroshell (Fig. I).

In the cialileo and Ulysses missions, a liquid-fueled Centaur rocket will be transported within the space shuttle payload bay. Any accident resulting in explosion of the shuttle and/or Centaur could expose the RT G to an explosive overpressure and a field of high-energy fragments. In previous tests series. we investigated module and clad responses to the impact of compact. highenergy fragments and to the flat-on impact of flyer plate fragments. ${ }^{1.3}$

The edge-on flyer plate tests were included in the Salety Verification Test (SVT) plan to provide information on the responses of the (iPHS module and hare capsules to the edge-on tmpact of high-energy flyer plate fragmenis. fecident analyses have shown that these lypes of impacts are possible in a launch vehicte or centaur explosion." Presumably. an explosise averpressure could renose the RTe; case and expesse the (iPHS modules to derect fragment interaction: above some threshold werpressure. the acroshell and cilss

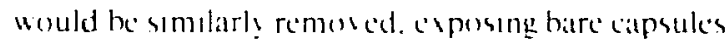




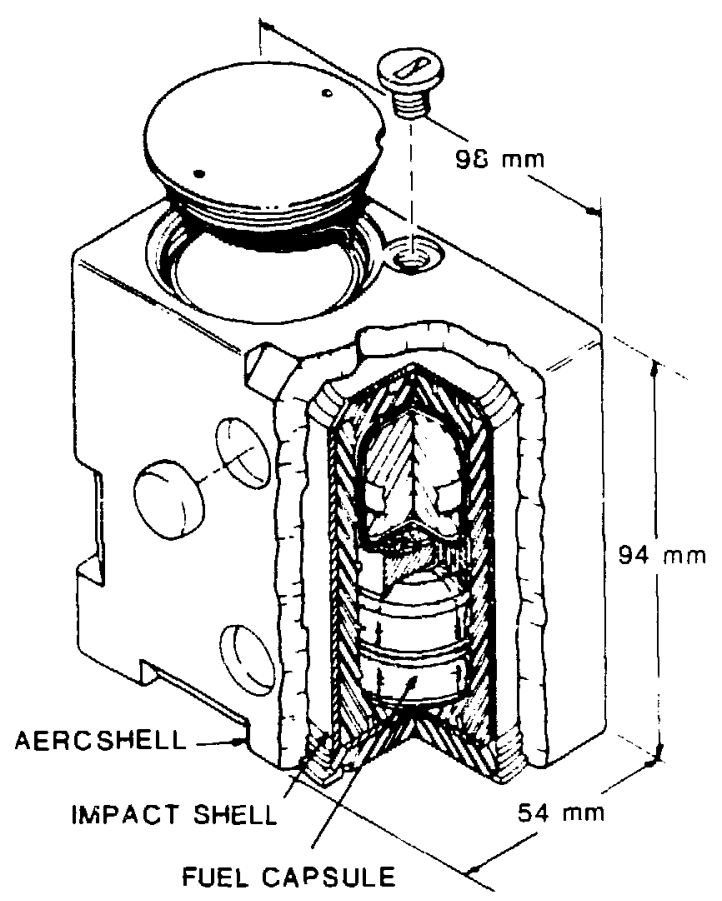

Fig. 1. Each GPHS module contans forr ${ }^{238} \mathrm{PuO}_{2-}$ fueled capsules.

\section{THE TEST PROGRAII}

The edge-on flyer plat: (FFP) te'sts simulated the impact of large plate-like fragments against fully loaded GPHS modules and against bare capsules. Because the test facility was not equipped to handle pluionium oxide. cither capsules fucled with $I^{\prime} O$, iprepared from depleted uranium-99.8\% $\left.{ }^{238} \mathrm{~L}\right)$ or metallic mass simulants (nickel or copper) were used as targets. The densit $\because$ ar: dimensions of each $1 . \mathrm{O}_{2}$ pellet were tailored to match the mass and configuration of an average plutonia pellet. Although plutonia pellets used in live
(jFHS modules are often fragmented (due to thermal stresses induced during encapsulation welding. degradanun caused by helium buildup. and internal stresses developed in (ransport). the extent of pellet breakup varies greatly: conseyesently. we chose not to simulate it. However. all of the $(!)_{2}$ pellets used in the EFP tests did contan cracks (as a result of the encapsulation welding).

\section{A. Components}

1. Targets. In the first two EFP tests. the target consisted of a (iPHS moduic loaded with four simulantfucled clads for as in the engineering test, four nickel mass simulants). The graphite module components were composed of night-quality material and were provided hy Los tlamos National Laboratory. The $\mathrm{UO}_{2}$ pellets and nickel mass simulants were also provided by Los Alamos. The iridium-alloy containment shells were flight-quality units provided by the Mound Facility. The iridium shells were welded over the urania pellets at Los Alamos.

The target in the last two EFP tests was a bare, simulant-fueled clad (or as in the engineering test, a copper mass simulant). As in the full-module tests, the fuel pellet and copper simulant were provided by Los Alamos, and the iridium-alloy shells were provided by the Mound Facility. However, the capsule used in the final EFP test was welded at the Savannah River Laboratory.

All of the $\mathrm{UO}_{2}$ and iridium-alloy test components are described in Table I.

2. Flyer Plates. The flyer plates used in the fullmodule EFP tests measured $203 \times 203 \times 3.18 \mathrm{~mm}$ and were composed of 2219-T87 aluminum (approximate Rockwell F hardness of 103). The flyer plate simulated a large aluminum fragment driven at high velocity (by a launch explosion) into the GPHS module stack. 22 ! $;$. T87 aluminum is used in several components of the space shuttle (the largest of which are the external tank

\begin{tabular}{|c|c|c|c|c|c|}
\hline \multirow[b]{2}{*}{ Test } & \multirow[b]{2}{*}{ Capsule } & \multicolumn{2}{|c|}{ Iridium Shell } & \multirow[b]{2}{*}{$\begin{array}{c}\mathrm{CO}_{2} \\
\text { Pellet" }\end{array}$} & \multirow[b]{2}{*}{$\begin{array}{c}\text { Fueled Capsule } \\
\text { Weight (g) }\end{array}$} \\
\hline & & $\begin{array}{l}\text { Vent } \\
\text { Cup }\end{array}$ & $\begin{array}{l}\text { Shield } \\
\text { Cup }\end{array}$ & & \\
\hline EFP-2 & IRG-121 & I.R289-3 & LR288-3 & $62-108$ & 201.0 \\
\hline EFP-2 & IRG-122 & I.R $289-5$ & I.R288-7 & $62-109$ & 204.6 \\
\hline EFP-2 & IRG-123 & I.R291-3 & I.R289-4 & $62-110$ & 204.1 \\
\hline EFP-2 & $196-124$ & I R $287-5$ & I.R285-8 & $62-111$ & 207.1 \\
\hline EFP-4 & $. M-47$ & $7550)-2$ & $7.549-4$ & $85-44$ & 206.4 \\
\hline \multicolumn{6}{|c|}{ Depleted ${ }^{23 s_{5}}$} \\
\hline
\end{tabular}


and forward bulkhead of the payload bay) that are possible fragment sources.

The bare-capsule EFP tests were designed to provide data on the response of a bare capsule to the edge-on impact of a high-energy fragment. These tests simulated a launch accident in which an explosive overpressure strips the GPHS capsules from their graphite shells and reduces the shutlle to a field of high-energy fragments. Because a significant portion of the shuttle fuselage is composed of 2024 aluminum. this alloy was specified as the flyer plate material: the desired plate dimensions were $203 \times 203 \times 3.53 \mathrm{~mm}$. Unfortunately, stocking errors resulted in the use of two other aluminum alloys: 2219-T87 (Rockwell F hardness 103 ) in the engineering test, and 5052-T0 (Rockwell $F$ hardness 68 ) in the simulant-fueled capsule test. In addition. the thickness of the plate used in the engineering test was $3.18 \mathrm{~mm}$ instead of $3.53 \mathrm{~mm}$. The mechanical properties of 2214 . T87. 2024. and 5052 aluminum are listed in Table 11.

\section{B. Procedures}

1. Full-Module Impacts. In the first two EFP tests. the target module was the center unit of a three-module stack. The top and bottom modules were bulk graphite blocks machined to the dimensions of a GPHS module. The module stack was supported on a hollow graphite pedestal. fixed to the baseplate of a SiC-elemen: furnace (Fig. 2): clevation of the target module was adjusted by: means of screws attached to the underside of the furnace baseplate. The furnace was suspended from an over-
Table II. Properties of Selected Aluminum Alloys"

\begin{tabular}{cccc}
\hline Alloy & $\begin{array}{c}\text { Heat } \\
\text { Treatment }\end{array}$ & $\begin{array}{c}\text { Minimum } \\
\text { Tensile Strength } \\
\text { (MPa) }\end{array}$ & $\begin{array}{c}\text { Minimum } \\
\text { Yield Strength } \\
\text { (MPa) }\end{array}$ \\
\hline 2024 & T0 & $\mathbf{1 8 5}^{\mathrm{b}}$ & $\mathbf{7 5}^{\mathrm{b}}$ \\
2219 & T87 & 441 & 358 \\
5052 & T0 & 172 & 65 \\
\hline
\end{tabular}

'Metals Handbook, Desk Edition, N. E. Boyer and T. L. Gall, Eds. (American Society for Metals, Metals Park, Ohio, 1985), pp. 6-34 to 6-43.

'These are nominal values; no minimum strengths are specified for 2024-T0 aluminum sheet.

hanging beam (Fig. 3). so that it could be rapidly raised and lowered over the module stack. The catch box was suspended in a similar manner, so that it could be moved into position ( $25 \mathrm{~mm}$ behind the module stack) after the furnace had been raised. Two calibrated chromel-alumel thermocouples (stainless steel sheathed) monitored the temperature of the test assembly: one thermocruple was positioned between the upper bulk module and the target module, and the other was wired to the surface of the module stack.

The impact velocities specified for the full-module tests mandated the use of a monorail rocket sled (to minimize air resistance), driven by a single rocket. A schematic of the full-module test setup may be seen in Fig. 4.

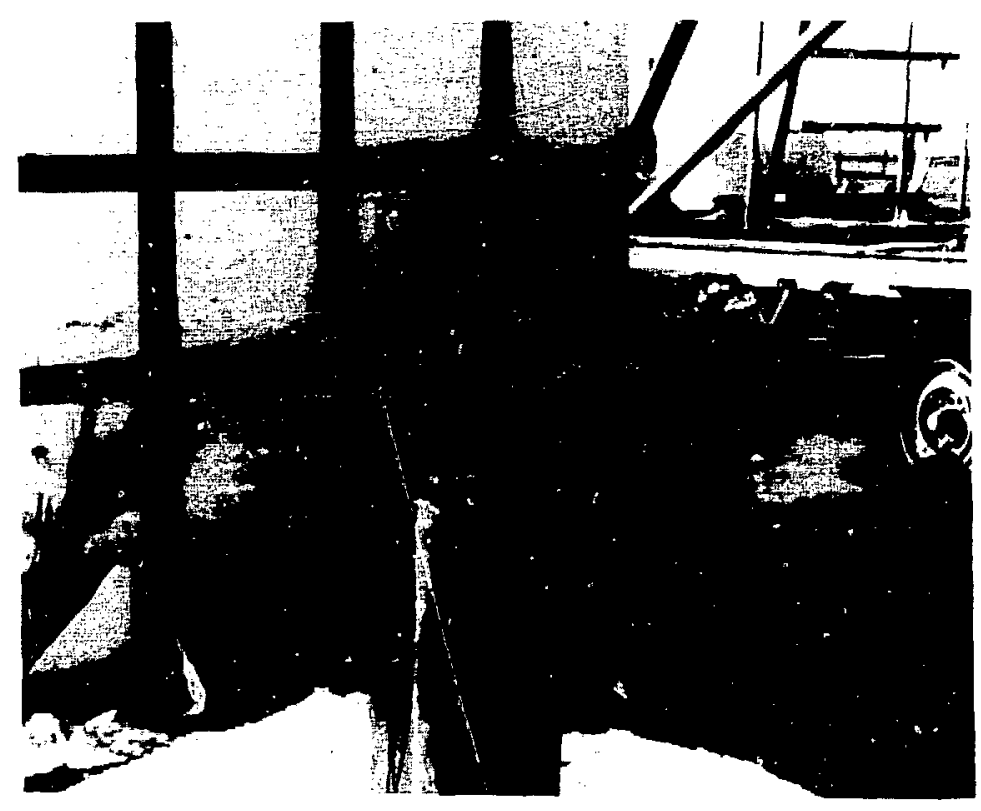

Fig. 2. The module stack was held in position by a graphite pedestal. 


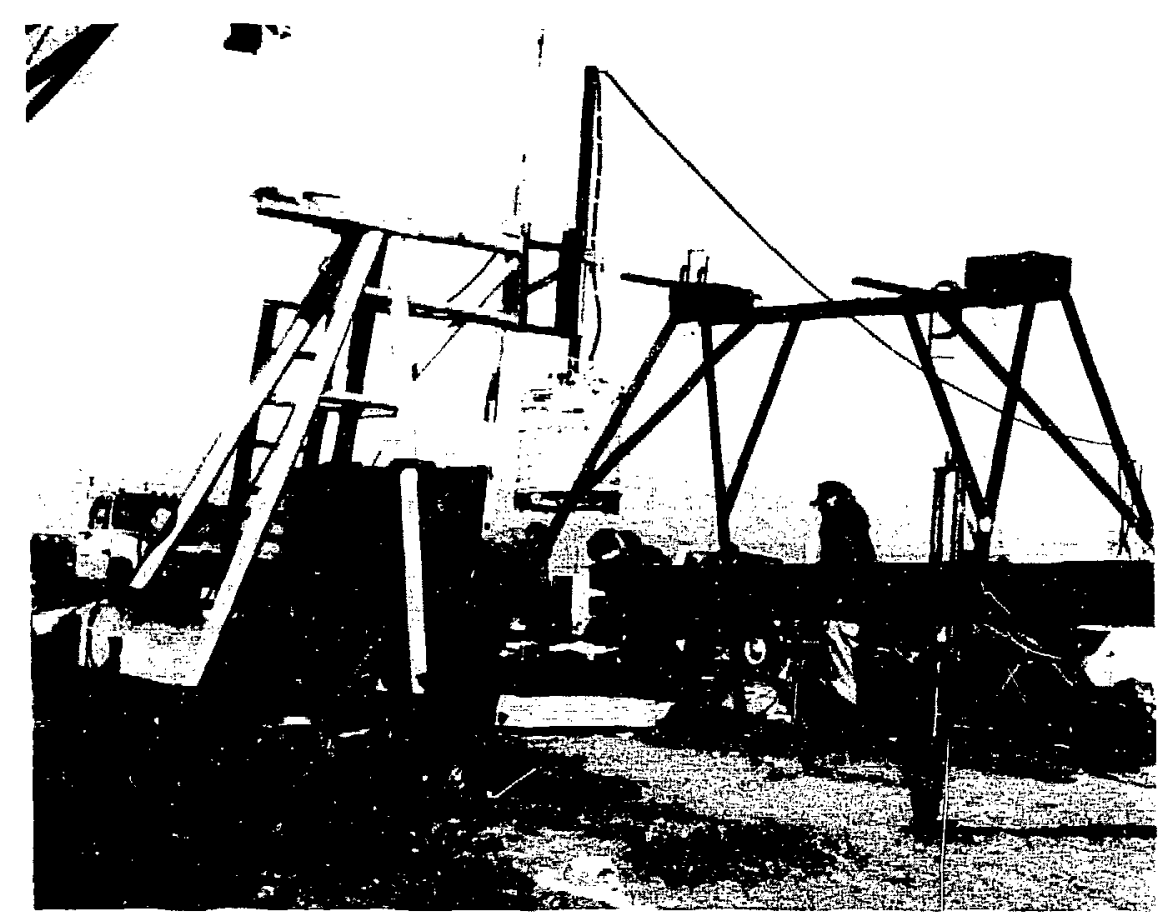

Fig. 3. The furnace could be rapidly raised and lowered over the module stack.

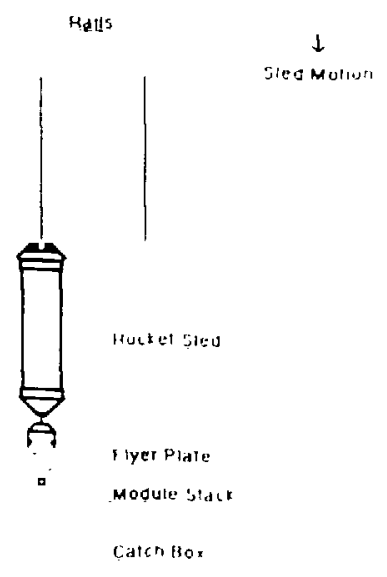

Fig. 4. The full-module EFP test setup.
To begin each lest. we retracted the vermiculite-filled catch box and lowered the furnace over the module stack. A flow of argon was introduced into the furnace. and the furnace was turned on. When the test assembly reached the desired temperature $\left(1091^{\circ} \mathrm{C}\right.$-the on-pad temperature of capsules within an RTG). we reduced power to the furnace. After the test components had soaked at temperature for $15 \mathrm{~min}$. the furnace was raised, the catch box moved into position (over the track). and the sled rocket was ignited. When the sled was approximately $50 \mathrm{~mm}$ from the test assembly, line charges released the flyer plate. After releasing the flyer plate. the sled passed beneath the catch box and struck a dir mound: the impact completely destroyed the sled. After each test. we emptied the vermiculite-filled catch box and recovered the remains of the test objects.

2. Bare-Capsule Impacts. The bare-capsule tests were conducted 21 months after the full-module impacts. In the interim. the test facilities had been considerably improved. The track was extended nearly I mile. and we were nou able to reuse the rocket sled after each test. In addition. because of the lower impact velocities used in the bare-capsule tests. it was possible to place the catch box farther from the impact point (and still capture all of the test components). The catch box was supported by steel legs and remained stationary 
throughout each test. The flyer plate was carried on a long boom extending from the side of the sled (to prevent a sled/catch box collision). The test setup used in the bare-capsule tests is shown in Fig. 5.

In the bare-capsule tests, the $\mathrm{UO}_{2}$-fueled clad (or mass simulant) was held in a graphite fixture (Fig. 6), positioned so the flyer plate would strike the capsule along its axial centerline (Fig. 7). As in the full-module tests, the fuel capsule was heated to the desired temperature in an open-ended ( $\mathrm{SiC}$-element) furnace. Clad temperature was monitored throughout the test by a split-junction (calibrated, type-S) thermocouple held in contact with the clad surface. Sled velocity was recorded by a series of break wires strung across the track. As in the fullmodule tests. the plate was released by line charges detonated just before impact. The plate impact was recorded by flash $x$-ray and by three high-speed cameras. After each test. we emptied the sawdust-filled* catch box and recovered the test components.

\section{RESLLTS}

All of the EFP tests are summarized in Table III. Details of individual tests are given below.

\section{A. EFP-1 (Full--Module Engineering Test)}

The objectives of this test were to verify that the test hardware would function as designed and to provide

*Indications of a vermiculite iridium reaction were obseried in overpressure tesis conducted in 1485.

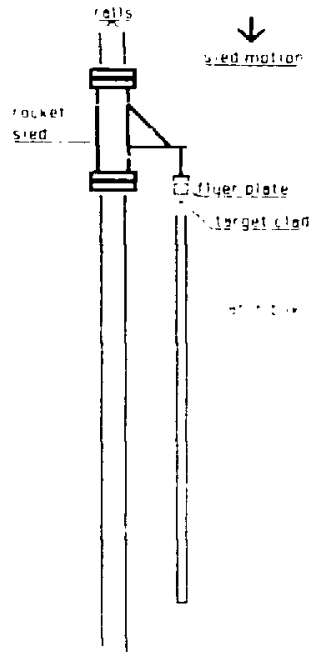

Fig. 5. Ihe hare-capsule IFP test selup.

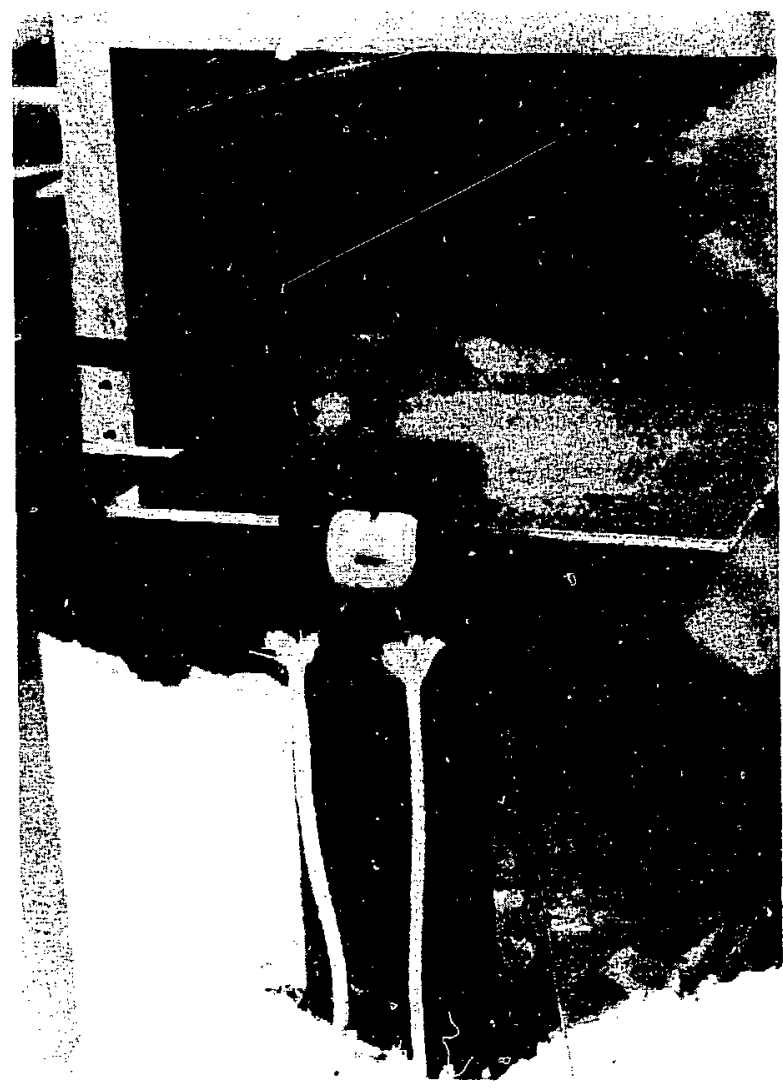

Fig. 6. The bare capsule was held in a graphite fixture altached to the furnace base.

preliminary information on module response. The target module contained four nickel mass simulants. The test assembly was slowly heated to $1118^{\circ} \mathrm{C}$ and was soaked at this temperature for $20 \mathrm{~min}$. At $\mathrm{T}-60 \mathrm{~s}$. the furnace was raised: at $\mathrm{T}-30 \mathrm{~s}$. the catch box moved into position ( $25 \mathrm{~mm}$ behind the module): and at $\mathrm{T}=$ $0 \mathrm{~s}$, the flyer plate impacted the module. Plate velocity at impact was $975 \mathrm{~m} / \mathrm{s}$ : module temperature was $1064^{\circ} \mathrm{C}$.

All the mass simulants were recovered in the eatch box. Each sinulant had been cleaved by the flyer plate (Fig. 8).

\section{B. EFP-2 (Full--Ilodule Tes1)}

The second fuli-module test was de signed to simulate the edge-on impact of a high-telecity tragment against a (iPHS module. The target module contained four (tO)fueled clads. The test assembly was slowl! heated to 1121 ( ( in 5 hours) and " as soaked at that comperalure for 15 min. At $T$ - 30 s. the furnate was rased. and at $T-15$ s. the catch bos moned into pusition $11 \mathrm{~T}=11 \mathrm{~s}$. 


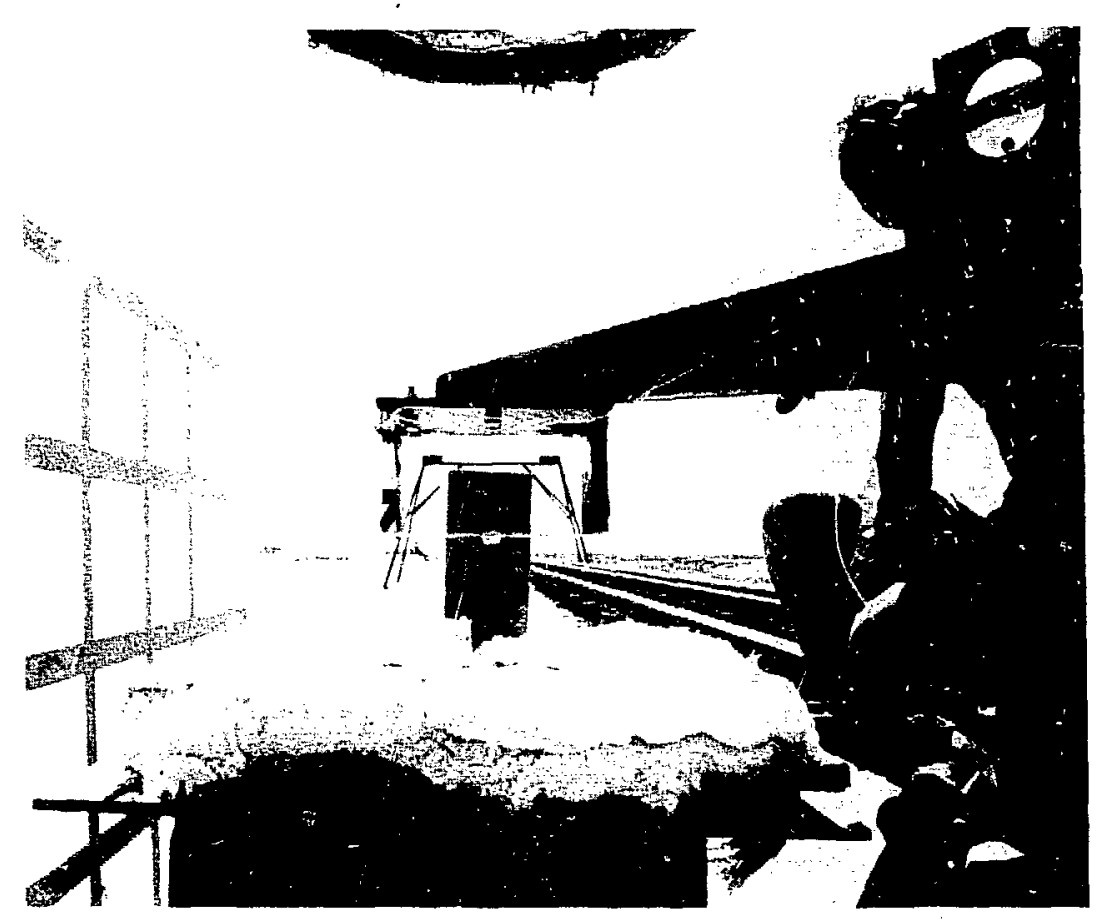

Fig. 7. The height of the furnace base was adjusted to ensure that the flyer plate would strike the clad along its axial centerline.

Table 111. Results of the EFP Impact Tests

\begin{tabular}{|c|c|c|c|c|c|c|c|}
\hline Test & Target & $\begin{array}{c}\text { Temperature } \\
\left({ }^{\circ} \mathrm{C}\right)\end{array}$ & $\begin{array}{c}\text { Plate } \\
\text { Material }\end{array}$ & & $\begin{array}{c}\text { Plate } \\
\text { Dimensions } \\
(\mathbf{m m})\end{array}$ & $\begin{array}{l}\text { Plate } \\
\text { Velocity } \\
(\mathrm{m} / \mathrm{s})\end{array}$ & Remarks \\
\hline EFP-1 & Full module & 1064 & $2219 \mathrm{Al}$ & 203.0 & $\times 203.0 \times 3.2$ & 975 & $\begin{array}{l}\text { Aeroshell fragmented; mass } \\
\text { simulants cleaved along axial } \\
\text { centerlines. }\end{array}$ \\
\hline EFP-2 & Full module ${ }^{b}$ & 1107 & $2219 \mathrm{Al}$ & 203.0 & $\times 203.0 \times 3.2$ & 918 & $\begin{array}{l}\text { Aeroshell fragmented; all clads } \\
\text { destroyed; total fuel release. }\end{array}$ \\
\hline EFP-3 & Copper slug & 600 & $2219 \mathrm{Al}$ & 203.0 & $\times 203.0 \times 3.2$ & 148 & $\begin{array}{l}\text { Plate struck slug along axial } \\
\text { centerline and deflected } \\
\text { downward as it penetrated } \\
>\mathbf{6 5} \% \text { of slug thickness. }\end{array}$ \\
\hline EFP-4 & $\mathrm{UO}_{2}$-fueled clad & 1081 & $5052 \mathrm{Al}$ & 203.0 & $\times 203.0 \times 3.5$ & 142 & $\begin{array}{l}\text { Plate struck clad along axial } \\
\text { centerline, opened a } 64.0-\times \\
5.3 \text {-mm breach and deflected } \\
\text { downward; } 25.36 \% \text { of fuel } \\
\text { simulant released. }\end{array}$ \\
\hline
\end{tabular}

Module was loaded with four nickel mass simulants.

${ }^{b}$ Module was loaded with four $\mathrm{UO}_{2}$-fueled clads.

The slug had a mass and diameter equivalent to those of a fueled clad. 


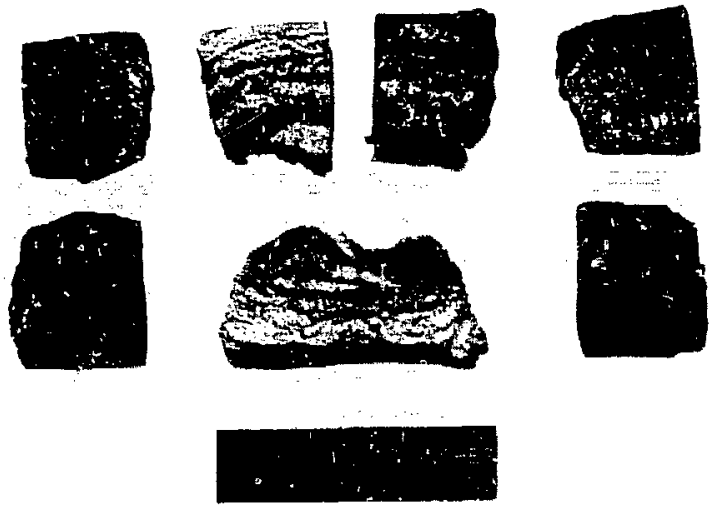

Fig. 8. The flyer plate cleaved all of the nickel mass simulants.

the plate impacted the module. Plate velocity at impact was $918 \mathrm{~m} / \mathrm{s}$; module temperáture was $1107^{\circ} \mathrm{C}$. Unfortunately, high-speed movies of the plate/module interaction revealed that one of the two line charges failed to detonate; one side of the plate was still attached to the sled at impact.

After the test. we examined the catch box contents and found enough iridium fragments to account for one fueled clad. A thorough search of the test site revealed numerous iridium fragments scattered within a $1-\mathrm{m}$ radius of the furnace base. A total of 21 fragments were recovered (Fig. 9), amounting to $169.7 \mathrm{~g}$ (approximately $85 \%$ of the iridium originally contained within the target module). Fragments of the aeroshell and impact shells were also recovered in the target area (Fig. 10).

\section{EFP-3 (Bare-Capsule Engineering Test)}

The primary objective of this test was to verify that the test hardware would perform as expected. The target was a copper slug with a weight and diameter equivalent to those of a $\mathrm{PuO}_{2}$-fueled capsule. Before the test, the copper slug was placed in the graphite holding fixture and the furnace was lewered over it. When the surface temperatlire of the copper reached $600^{\circ} \mathrm{C}$, the furnace was raised and the sled rockets ignited. Plate velocity at inipaci was $147.8 \mathrm{~m} / \mathrm{s}$.

After the test, we recovered the copper slug (Fig. 11) from the catch box. The deformed flyer plate was discovered on the ground approximately $1 \mathrm{~m}$ from the catch box opening. Macroscopic examination revealed that the flyer plate had cleaved through $65 \%$ of the slug. The contact portion of the flyer plate was bent sharply downward (Fig. 12). Subsequent examination of flash radiographs verified that the plate struck the slug squarely along its axial centerline and was forced downward as it penetrated the copper (Fig. 13).

\section{EFP-4 (Bare-Capsule Test)}

The target used in the final EFP test was a bare, simulant-fueled clad (capsule M-47). One day prior to the test, we conducted a series of temperature-drop tests to determine the furnace temperature and time required to give a clad impact temperature of $1091^{\circ} \mathrm{C}$. The results indicated that an initial clad/furnace temperature of $1290^{\circ} \mathrm{C}$ would give a $1091^{\circ} \mathrm{C}$ clad temperature $43 \mathrm{~s}$ after the furnace started to rise. Although only $8 \mathrm{~s}$ were required to raise the furnace to its test position (secured

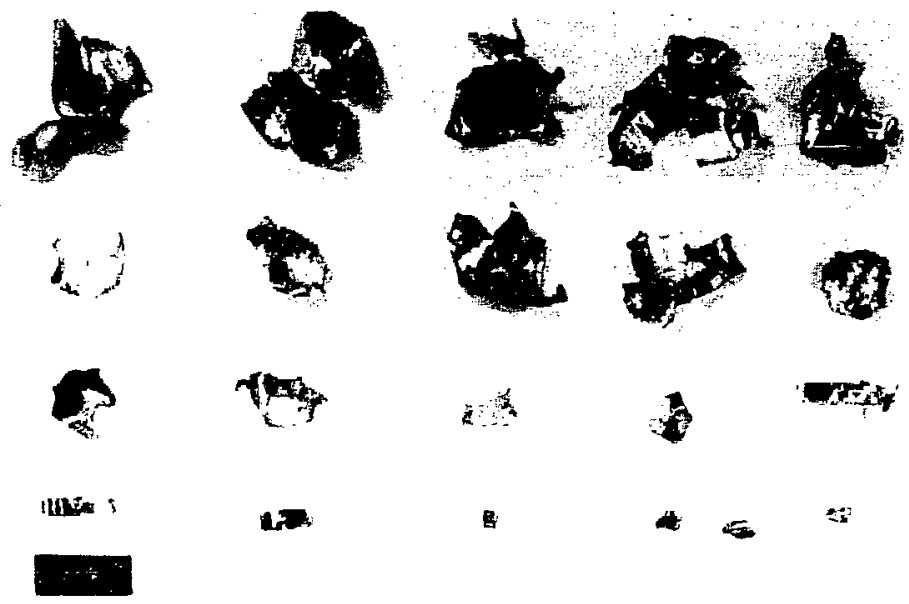

Fig. 9. Twenty-one iridium fragments were recovered from the EFP-2 test site. 


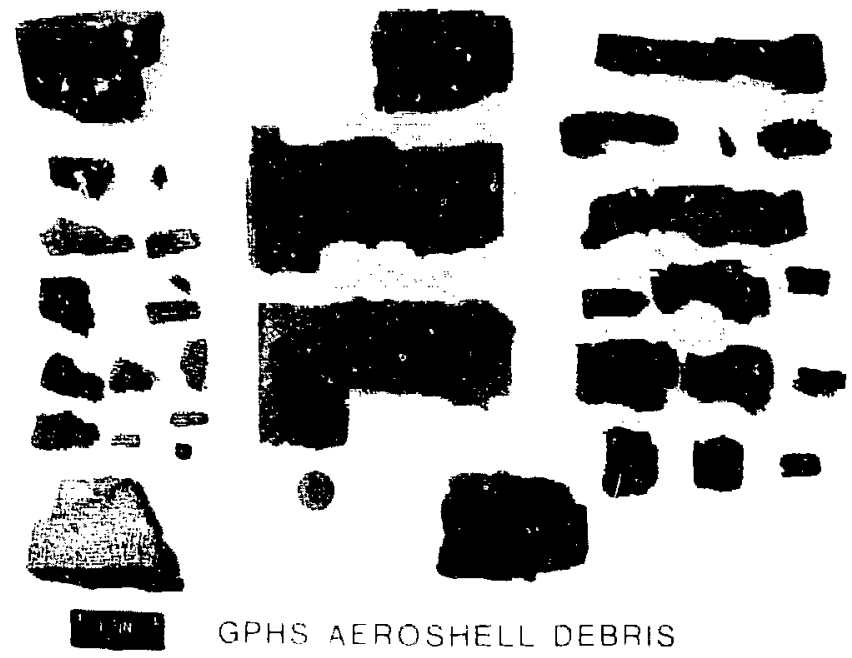

Fig. 10. Fragments of the EFP-2 aerushell and impact shelis were also recovered.

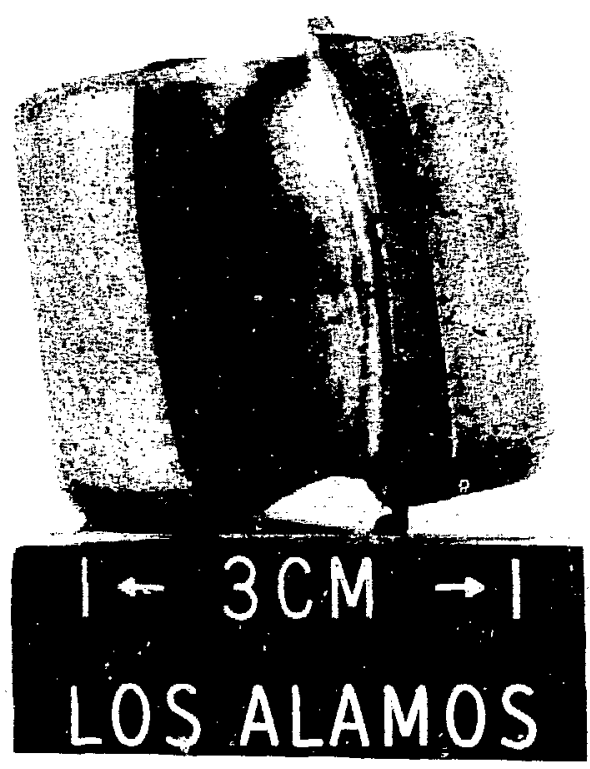

(a)

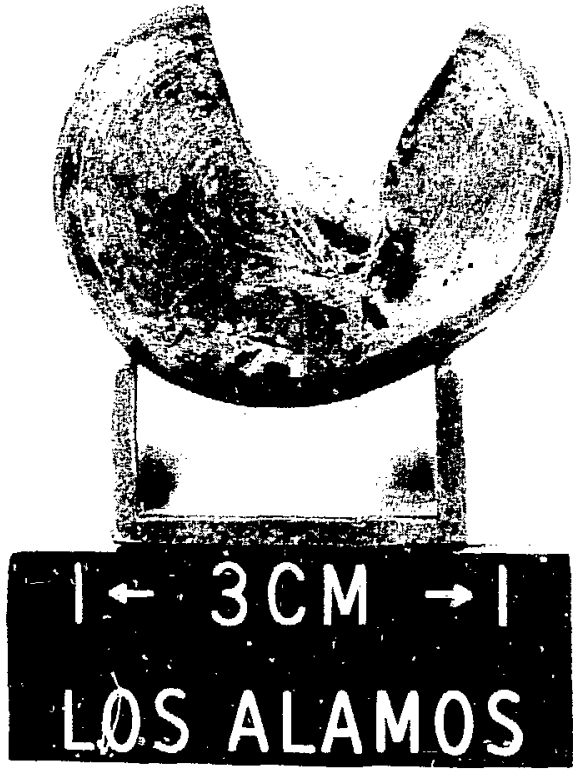

(b)

Fig. 11. The copper slug was recovered from the sawdust-filled catch box. (a) Impact face and (b) end: both at 1.5X. 


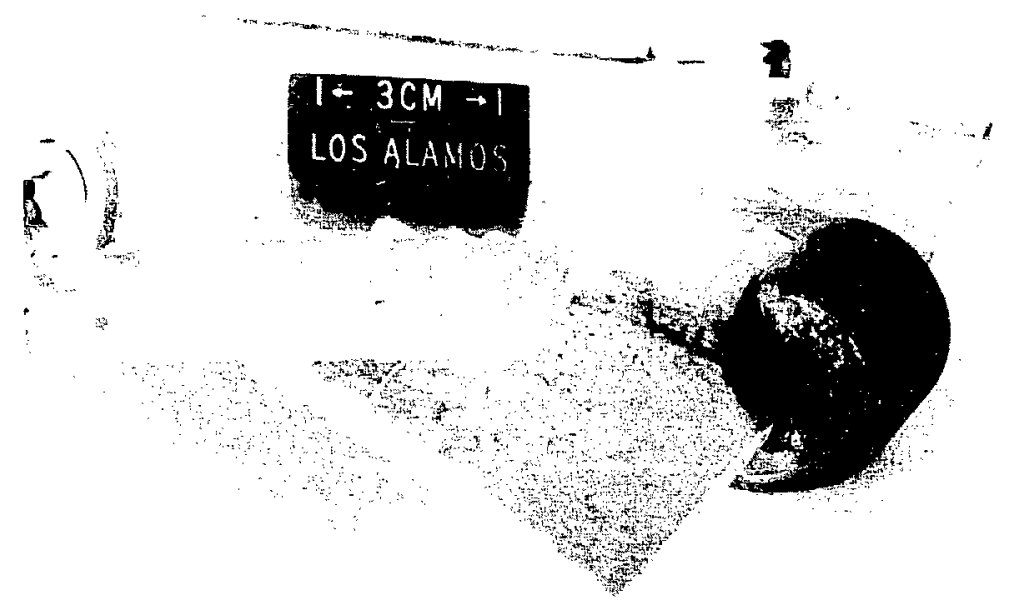

Fig. 12. The flyer plate cleaved through $65 \%$ of the copper slug.

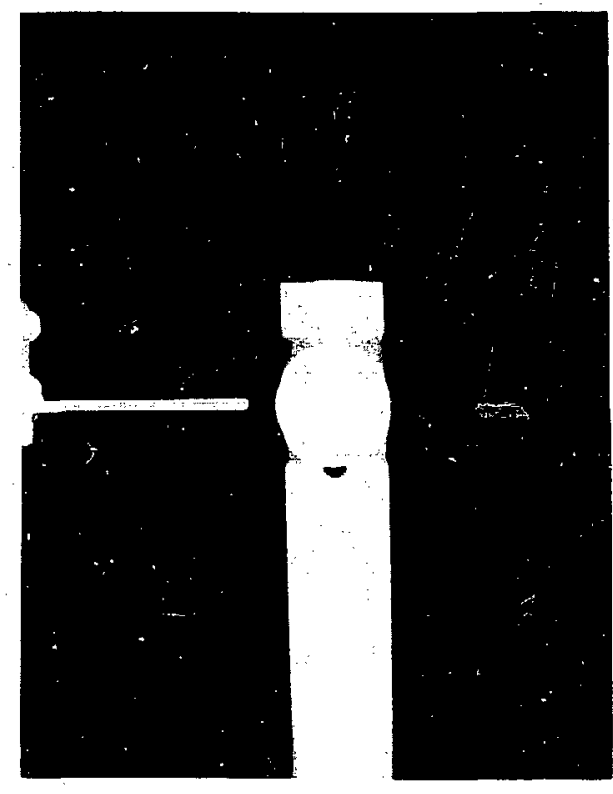

(a)

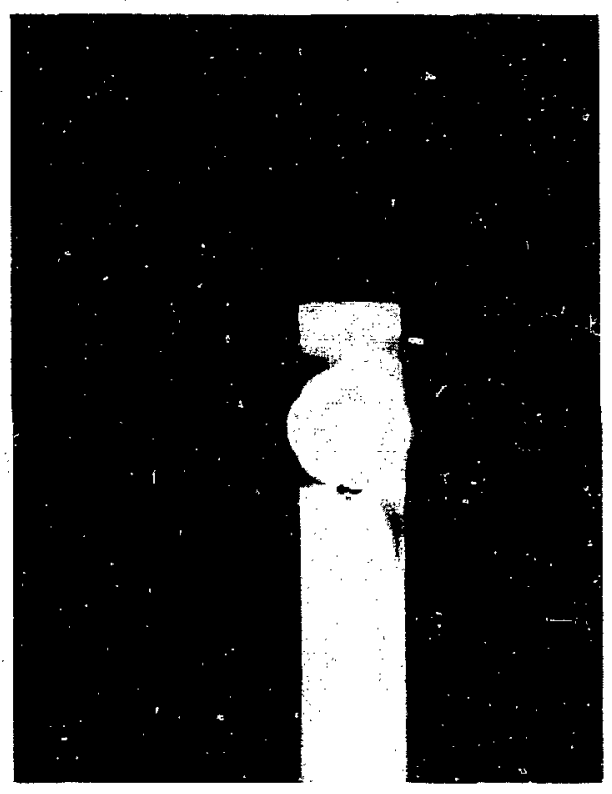

(b)

Fig. 13. Radiographs of the EFP-3 impact verify that the plate struck the copper slug along its axial centerline. (a) Preimpact alignment of plate and slug. and (b) double exposure showing positions at impact and just after. 
to an overhanging beam), we felt that a 42-s delay in igniting the rockets provided a wide safety margin (Sandia National Laboratories personnel calculated that I s would be required for the sled to travel from its starting position to the target).

After the initial clad/furnace temperature and firing sequence had been established, the furnace was lowered back onto the test platform and heated $10600^{\circ} \mathrm{C}$. The clad was soaked at this temperature for 14 hours (in an argon atmosphere) to reduce heat-up time the next day.

On the following morning, the clad was heated from $600^{\circ} \mathrm{C}$ to $1317^{\circ} \mathrm{C}$ in 4 hours. When the clad temperature reached $1317^{\circ} \mathrm{C}$, power to the furnace was reduced. and the temperature slowly dropped to $1290^{\circ} \mathrm{C}$ (the time interval between the two temperatures was approximately $10 \mathrm{~min}$ ). When the clad temperature reached $1290^{\circ} \mathrm{C}$, the firing sequence was initiated: at $\mathrm{T}-35 \mathrm{~s}$, the furnace was secured in its test position: and at $\mathrm{T}-1 \mathrm{~s}$. the sled rockets were ignited. Plate velocity at impact was $142.3 \mathrm{~m} / \mathrm{s}$; clad temperature was $1081^{\circ} \mathrm{C}$.

Unfortunately, one of the line charges designed to release the plate failed to detonate; the plate struck the capsule while still attached to the sled boom. Flash radiographs of the impact (Fig. 14) verified that the plate struck the capsule squarely along its axial centerline. As in the engineering test. the plate deflected downward after striking the capsule. The resulting plate geometry propelled the capsule forward and upward at a $45^{\circ}$ angle. The capsule completely missed the catch box and was recovered $266 \mathrm{~m}$ from the test platform (Fig. 15).

After striking the target, the flyer plate impacted the steel catch box. Because one line charge did not detonate, the plate fragmented (two pieces) as it ripped free of the sled boom (Fig. 16). Fortunately. the plate edge that struck the capsule remained attached to the largest fragment and was relatively undisturbed (Fig. 17). Both plate fragments were recovered within $1 \mathrm{~m}$ of the test platform.

Macroscopic examination of the recovered capsule revealed that it was breached by an axial crack $(64.0 \times$

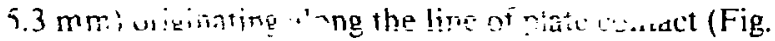
ib). The ureaching crack extended beyond the impact face and propagated along the circumferences of the vent and blind ends (Figs. 18d and 18e). Clad sections adjacent to the breach on the impact face were discolored by a grayish surface laver (Fig. 18a) that appeared to have resulted from an iridium/aluminum reaction. In addition. the trailing facc of the capsule contained an area of deep striations (Fig. 18c) that apparently resulted from contact with the concrete track bed.

After macroscopic examination, the capsule was opened and then sectioned for metallography. Small samples of each cup were also obtained for spectrographic analysis; results of these analyses are presented

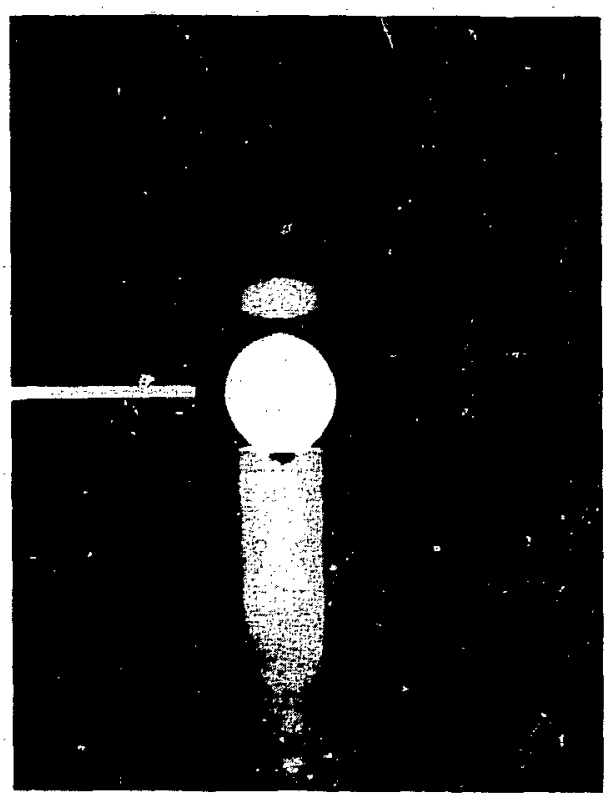

(a)

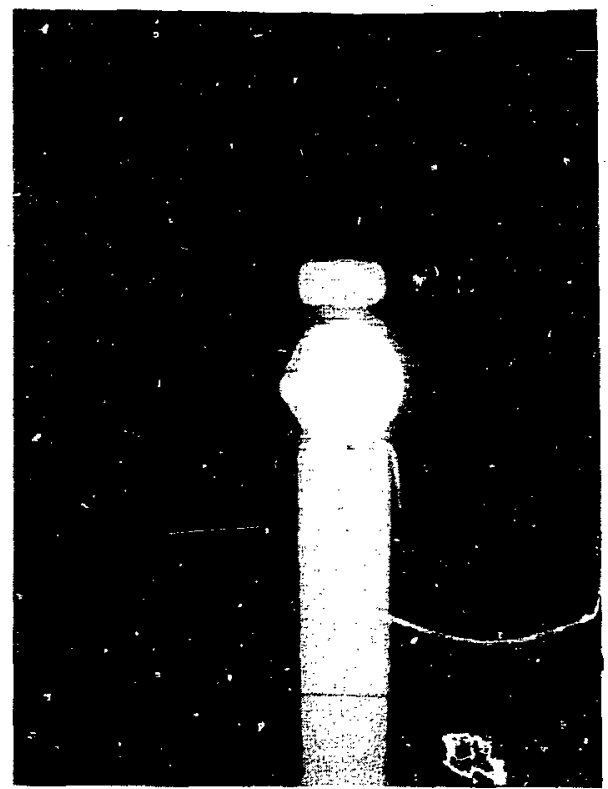

(b)

Fig. 14. Radiographs of the EFP-4 impact verify that the plate struck capsulc M-47 along its axial centerline. (a) Preimpact alignment of plate and capsule, and (b) douhle cxposure showing positions at impact and just after. 


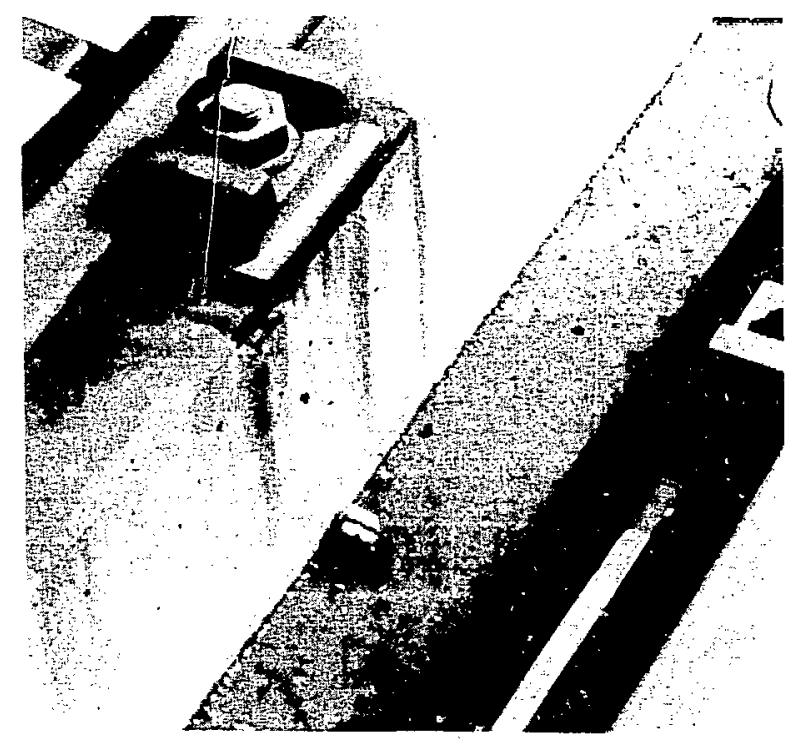

Fig. 15. Capsule $M-47$ was recovered $266 \mathrm{~m}$ from the point of impact in the water trough between the sled rails.

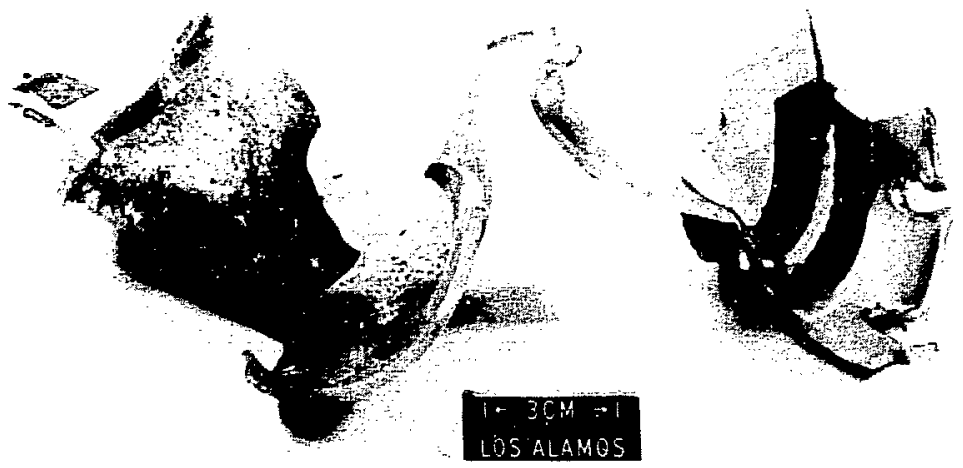

Fig. 16. Impact with the steel catch box severely deformed the EFP-4 flyer plate. 


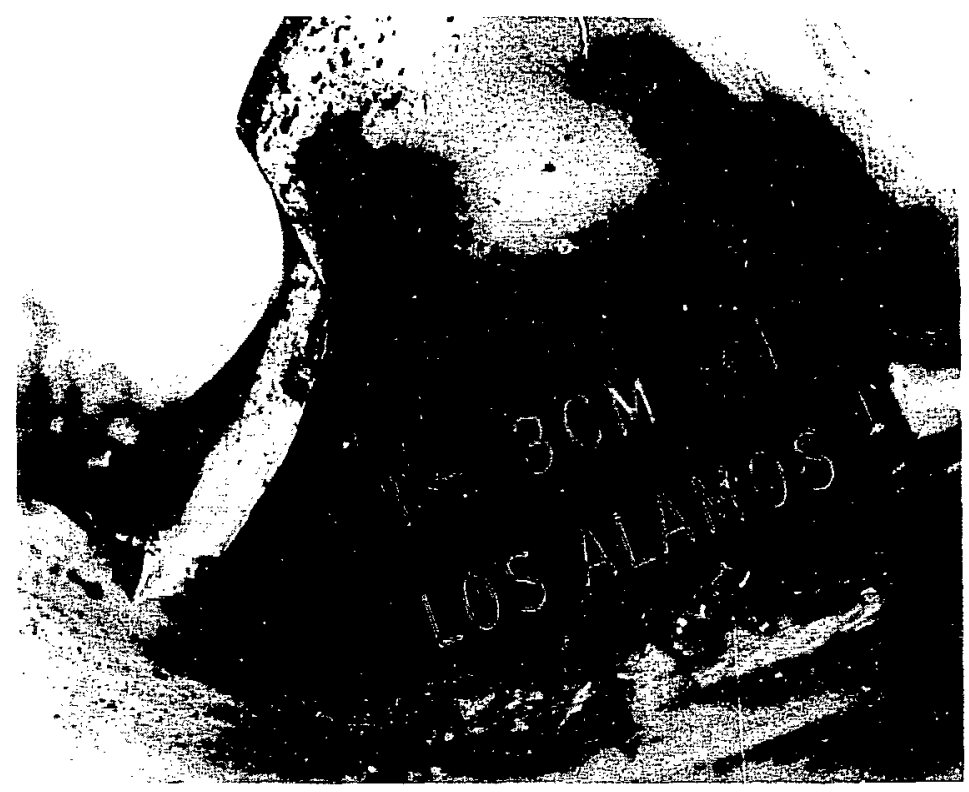

Fig. 17. The portion of the EFP-4 flyer plate that struck capsule M-47 was relatively undisturbed by the catch box impact.

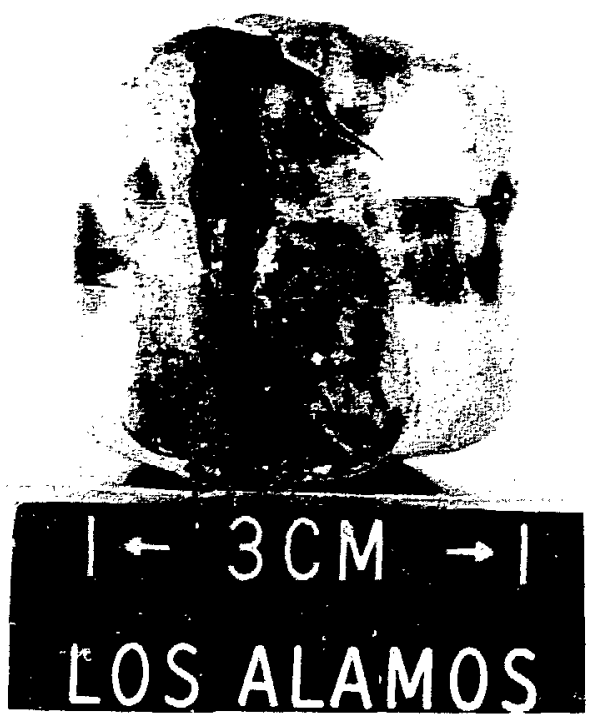

(a)

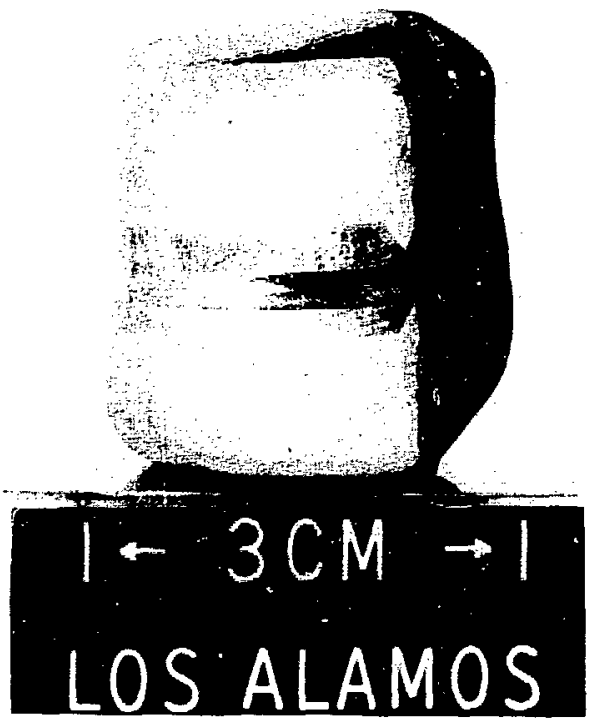

(b)

Fig. 18. Capsule $M-7$ was breached by a wide axial crack. (a) Impact face. (b) profile, (c) trailing face, (d) vent end, and (e) blind end; all at $1.5 \mathrm{X}$. 


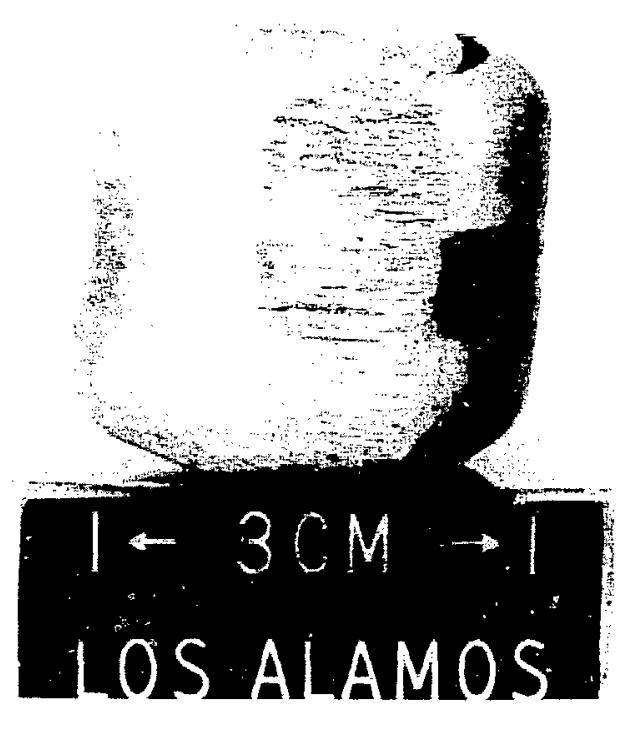

(c)

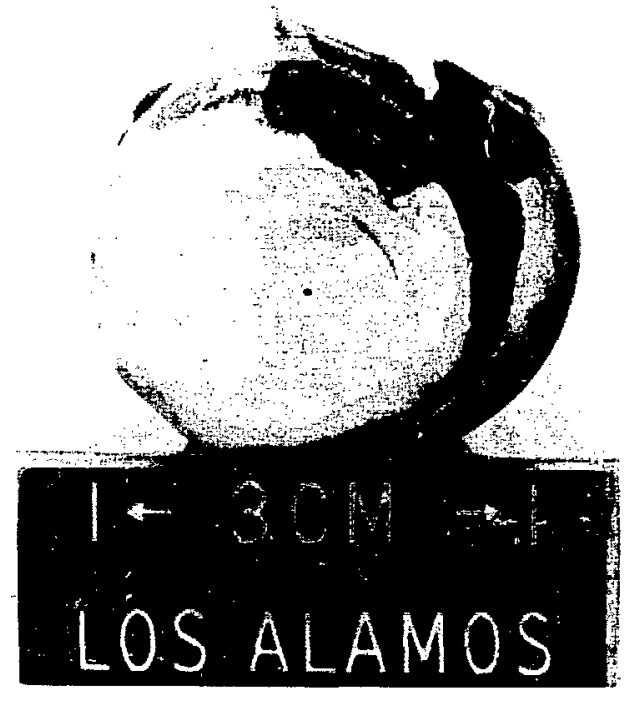

(d)

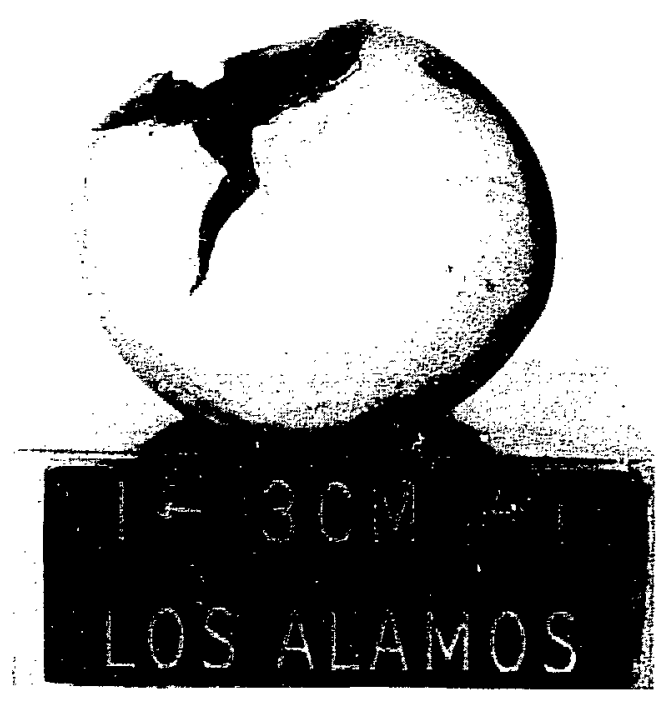

(e)

Fig. 18. (cont) 
in Table IV. The simulant fuel was weighed and sub. mitted for particle size analysis; results of the sieve analysis are listed in Table $\mathrm{V}$. Comparing the original fuel pellet weight with the as-recovered weight revealed that $25.36 \%$ of the simulant $(38.496 \mathrm{~g})$ had been released.

Microscopic examination of a transverse shield cup section (Fig. 19) revealed small penetrating cracks on one side of the main breach. All of the cracks had a brittle, intergranular appearance; the sections adjacent to the main breach were only slightly deformed (Fig. 20). Although no evidence of an iridium/aluminum reaction was observed in the main breach (Fig. 21), all of the other cracks were coated with a thin gray layer (Figs. 22 through 24). The gray coating was even observed within a narrow, (apparently) internal crack (Fig. 25). EDS (Energy Dispersive Spectrometry) analysis verified that the gray material was a compound of aluminum arid iridium, with approximately equal amounts of each element. An electron micrograph of one crack is shown in Fig. 26a, and elemental dot maps (for aluninum and iridium) of the same area are shown in Figs. $26 \mathrm{~b}$ and $26 \mathrm{c}$.

Examination of a transverse vent cup section revealed features similar to those observed in the shield cup. Several narrow cracks penetrated the capsule wall on one side of the main breach, and all of the cracks had a brittle, intergranular appearance. In this section however, even the main breach was coated with a thin layer of iridium/aluminum reaction product (Fig. 27).

The vent and weld shield cups both had very fine grained microstructures. The vent cup contained an average of 25.1 grains $/ 0.635 \mathrm{~mm}$ nominal wall thickness, and the shield cup averaged 27.0 grains/thickness.

Table IV. Results of Spectrographic Analyses of the M-47 Iridium Cups

\begin{tabular}{ccc}
\hline Element & $\begin{array}{c}\text { Shield } \\
\text { Cup } \\
(\mathrm{ppm})\end{array}$ & $\begin{array}{c}\text { Vent } \\
\text { Cup } \\
(\mathrm{ppm})\end{array}$ \\
\hline $\mathrm{Cu}$ & 30 & $\mathbf{2 0}$ \\
$\mathrm{Mg}$ & ND & ND \\
$\mathrm{Ca}$ & ND & ND \\
$\mathrm{Al}$ & 80 & 80 \\
$\mathrm{Si}$ & $\mathbf{1 0}$ & 30 \\
$\mathrm{Cr}$ & ND & ND \\
$\mathrm{Fe}$ & 30 & 30 \\
$\mathrm{Ni}$ & ND & ND \\
$\mathrm{Pt}$ & ND & ND \\
\hline
\end{tabular}

Not detected.
Table V. Sieve Analysis of Simulant Fuel Remaining in the EFP-4 Target Clad"

\begin{tabular}{|c|c|c|c|}
\hline \multicolumn{3}{|c|}{$\begin{array}{c}\text { Particle Size } \\
\text { Range }(\mu \mathrm{m}) \\
\end{array}$} & Weight Fraction \\
\hline & 0.4667 \\
\hline \multicolumn{3}{|c|}{+2000 to 6000} & 0.3327 \\
\hline \multicolumn{3}{|c|}{+841 to 2000} & 0.1317 \\
\hline \multicolumn{3}{|c|}{+420 to 841} & 0.0406 \\
\hline \multicolumn{3}{|c|}{+177 to 420} & 0.0187 \\
\hline \multicolumn{3}{|c|}{+125 to 177} & 0.0031 \\
\hline \multicolumn{3}{|c|}{+74 to 125} & 0.0027 \\
\hline \multicolumn{3}{|c|}{+44 to 74} & 0.0013 \\
\hline \multicolumn{3}{|c|}{+30 to 44} & 0.0007 \\
\hline \multicolumn{3}{|c|}{$+\quad 20$ to 30} & 0.0003 \\
\hline \multicolumn{3}{|c|}{+10 to } & 0.0004 \\
\hline+ & 9 to & 10 & 0.0001 \\
\hline+ & 8 to & 9 & 0.0001 \\
\hline+ & 7 to & 8 & 0.0000 \\
\hline & 6 to & 7 & 0.0001 \\
\hline+ & 5 to & 6 & 0.0001 \\
\hline+ & 4 to & 5 & 0.0002 \\
\hline+ & 3 to & 4 & 0.0002 \\
\hline \multirow{2}{*}{$\begin{array}{l}+ \\
+\end{array}$} & 2 to & 3 & 0.0002 \\
\hline & 1 to & 2 & 0.0001 \\
\hline+ & 0 to & 1 & 0.0000 \\
\hline \multicolumn{3}{|c|}{$<10 \mu \mathrm{m}$} & 0.0011 \\
\hline \multicolumn{4}{|c|}{$\begin{array}{l}\text { Performed in accordance with procedure } \\
\text { MST-5-C-82-19, Operation 9, 1ssue 1, Rev. } \\
\text { 1, Particle Size Determination. }\end{array}$} \\
\hline
\end{tabular}

\section{DISCUSSION}

The results suggest that the edge-on impact of a 3.2mm-thick, 2219-T87 aluminum-alloy plate traveling at $915 \mathrm{~m} / \mathrm{s}$ will cause the complete release of fuel from: capsules contained within a GPHS module. In both fullmodule tests (EFP-1 and EFP-2), the aluminum flyer plate penetrated the graphite module components and breached the iridium cladding (in EFP-1, it cleaved the nickel mass simulants). Although the EFP-2 flyer plate did not fully disengage from the rocket sled (due to the misfiring of one line charge). the added support apparently had no effect: all four clads breached and released their entire fucl inventory. The amount of clad damage (EFP-2) and the appearance of the nickel simulants (EFP-1) suggest that both plates remained integral during module impact. The observed plate fragmentation probably resulted from postimpact interactions with the catch box and other test hardware. 
The results of the bare-capsule impacts (EFP-3 and EFP-4) suggest that the threshold velocity of a $3.5-\mathrm{mm}$ thick, 5052 aluminum-alloy plate sufficient to cause a breach is approximately $140 \mathrm{~m} / \mathrm{s}$. However. this conclusion is based on the assumption that the flyer plate is free to deform during impact. In both bare-capsule tests. the flyer plate struck the target (a copper slug in EFP-3 and a simulant-fueled capsule in EFP-4) and deflected downward. Although the EFP-4 flyer plate did not disengage from the rocket sled (due to the misfiring of one line charge. which was similir to the problem in EFP-2). radiographs (Fig. 14) of the impact and postmortem examination of the plate fragments verify that the plate deflected.

Although the EFP-4 flycr plate was composed of 5052-T() aluminum instead of the desired 2024-T0. the test results were probably unaffected by the substitution As the data in Taóle 11 indicate. there are only minor differences in the mechanical properties of 20?4-T() and 5052-T0.

The plate deflections observed in the bare-capsule impact tests and the lack of any similar deflections in the full-module impacts suggest that plate rigidity may be an important factor in the amount and severity of capsule damage. In the first two tests, as the flyer plate penetrated the GPHS module. it was restrained both above and below by the masses of the graphitc components. Even when the plate edge struck the fueled clads (or nickel mass simuiants). buckling was prevented by the mass of the previously cleaved graphite: the stabilized plate completely penetrated the fuel capsules. In the bare-capsule impacts howcver. the plate was free to deform and began to buckle immediately. In EFP-4. as the plate buckled. the edge deflected down and away from the capsule centerline. The plate/capsule interaction observed in EFP-4 suggests that an increase in platc velocity would not necessarily result in a larger clad breach. If the plate is free to deflect and the capsule is free to spin away from the plate edge. increasing the plate velocity would directly increase only the amount of spin imparted to the capsule. Further. as plate vclocity increases. the likelihood and severity of buckling also increase.

If the amount and severity of plate buckling have a significant effect on capsule damage. then the elastic modulus of the flycr plate material is of primary importance. Differences in the buckling of dimensionally identical plates composed of different materials, loaded in the same manner. result only from differences in the elastic moduli. The respective material strengths have no effect on the onset of buckling: they determine only the amount of deflection before failure. Consequently. the specific aluminum alloy used in cach test is of little importance: all aluminum alloys have the same clastic modulus.
The intermetallic deposits observed on the EFP-4 target clad (Figs. 22 through 25) suggest that the iridium/aluminum reaction can occur very rapidly. Although an energetic reaction has been previously observed between molten aluminum and solid iridium held in contact for relatively long periods. or arc-melted together,' there have never been any indications that this reaction could occur in the shor contact time experienced in this test. A possible explanation of the test results is that, as the aluminum plate struck the clad, small plate fragments were abraded (possibly extruded) into cracks and rough spots on the iridium surface; as the clad spun up and away from the plate, the heated capsule melted the aluminum and allowed it to react.

The results of spcctrographic analyses (Table IV) of the iridium cups used in the EFP-4 target clad indicate that this capsule was chemically similar to other clads used in the SVT program. However, the average grain sizes of the iridium cups (the vent cup contained an average of 26.1 grains/thickness, and the shield cup averaged 27.0 grains/thickness) were slightly smaller than those of typical plutonia-fueled clads (which generally range between 15 and 25 grains/thickness). Although reductions in grairi size are directly related to increases in ductility and toughness. the small difference in grain size between the EFP-4 target clad and typical plutonia-fueled clads would not be expected to have significantly altered the impact response.

\section{v. CONCLUSIONS}

(1) The edge-on impact of a 3.2-mm-thick, aluminum-alloy (2219-T87) plate traveling at $915 \mathrm{~m} / \mathrm{s}$ will cause the complete release of fuel from capsules contained within a GPHS mudule.

(2) It appears that the threshold velocity of a 3.5mm-thick, (5052-T0) aluminum-alloy plate sufficient to breach a bare fueled clad is approximately $140 \mathrm{~m} / \mathrm{s}$.

(3) The results suggest that the severity of clad damage is determined in part by the stiffness (resistance to buckling) of the impacting plate. plate orientation at impact, and the amount of restraint imposed on the capsule (the force holding it in the path of the plate).

\section{RECOMMENDATIONS}

(1) Additional full-module impacts should be conducted to determine the threshold plate velocity required to initiate breaching cracks in the fueled clads.

(2) High-velocity bare-capsule EFP tests should be conducted to deternine if clad damage will increase with increasing plate velocity. 
(3) At least one full-module and one bare-capsule test should be conducted at the same velocity to determine whether the graphite components reduce plate buckling and thereby increase clad damage.

(4) Because the elastic moduli of both titanium and steel are significantly higher than that of aluminum, at least one fuli-module or bare-capsule test should be conducted to evaluate the effect of these materials on capsule response.

(5) The formation of iridium/aluminum compounds should be thoroughly investigated. and the mechanical and thermodynamic properties of alt likely compounds should be determined.

(6) The response of capsules containing surface deposits of iridium/aluminum reaction product to subsequent impacts should be investigated.

\section{ACKNOWLEDGMENTS}

I would like to thank the following people for their valuable contributions: $M$. Anstey for fabricating graphite test fixtures on very short notice. A. Herrera for machining the plate used in EFP-4 on even shorter notice, D. Morse for photographing the last two tests and for helping conduct the tests. J. Archuleta for performing the metallographic and EDS analyses, and $R$. Tate for supervising the first two tests.

\section{REFERENCES}

1. T. G. George, R. E. Tate, and K. M. Axler, "GeneralPurpose Heat Source Development: Safety Verification Test Program. Bullet/Fragment Test Series," Los Alamos National Laboratory repon LA-10364MS (May 1985).

2. T. G. George. "General-Purpose Heat Source Development: Safety Verification Test Program, Titanium Bullet/Fragment Test Series," Los Alamos National Laboratory report L.A-10724-MS (June 1986).

3. T. A. Cull and D. Pavone, "General-Purpose Heat Source Development: Safety Verification Test Program. Flyer Plate Test Series," Los Alamos National Laboratory report LA-10742-MS (September 1986).

4. "GPHS Safety Verification Test Series Procedure Manual," Los Alamos National Laboratory document MST-5-C-83-19 (April 1983).

5. "Space Shuttle Data for Planetary Mission Radioisotope Thermoelectric Generator (RTG) Safety Analysis," NASA document JSC-08116 (February 15,1985 ), Section 6.0 (fragment models).

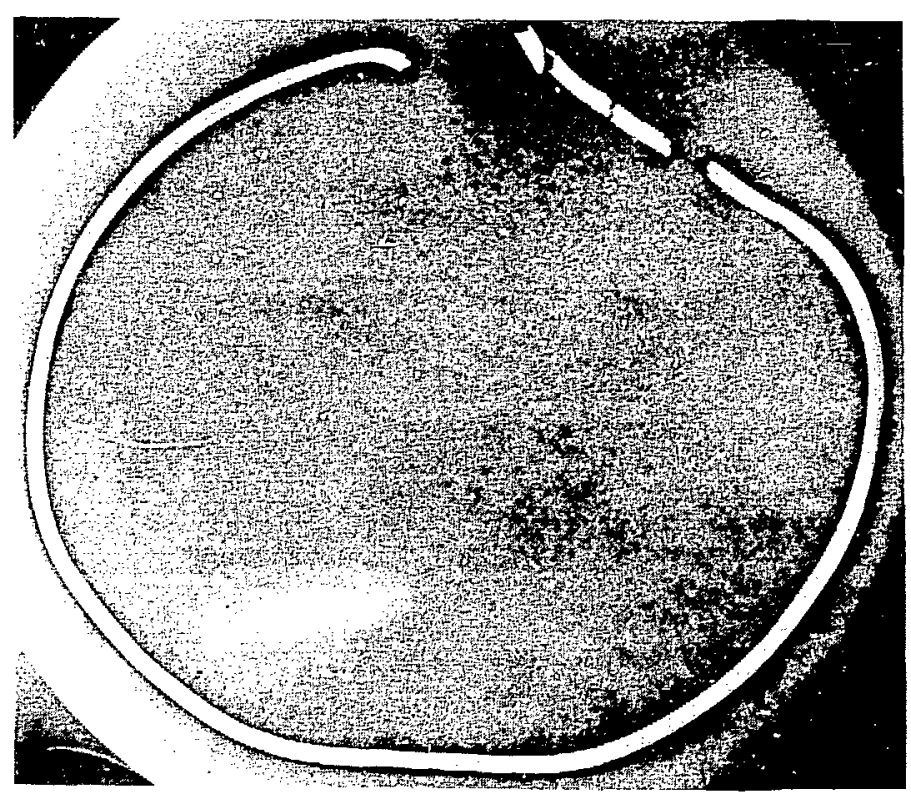

Fig. 19. Several small cracks were visible in a section of the M-47 shield cup that contained the main breach; as polished, 4X. 


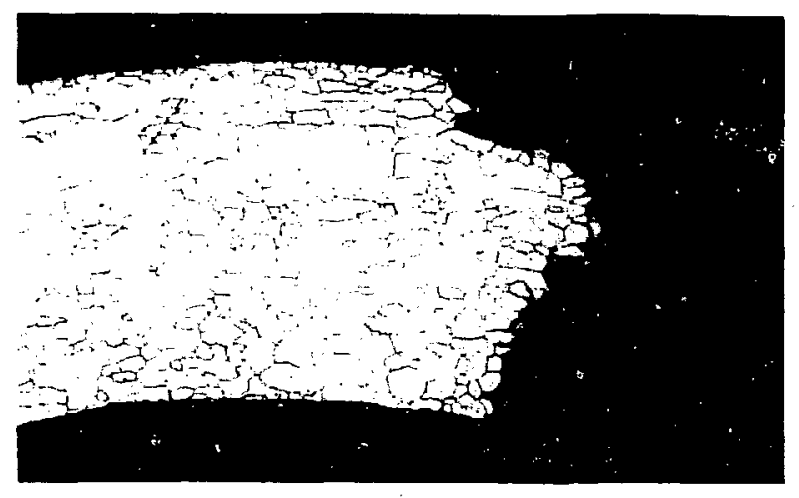

(a)

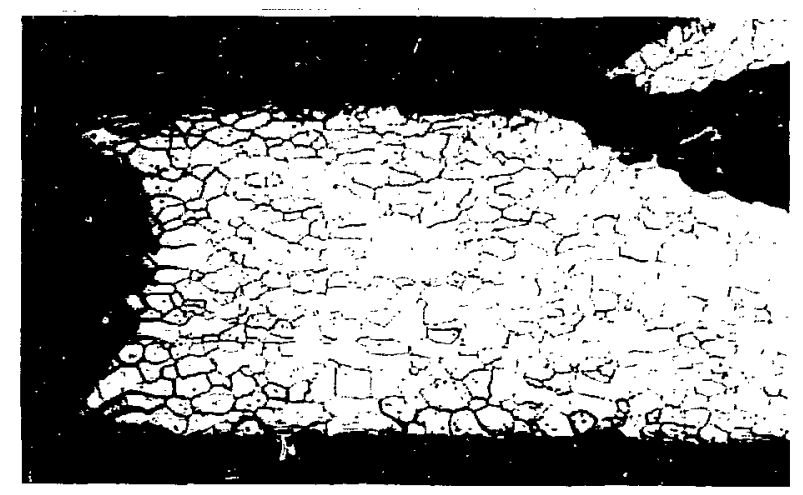

(b)

Fig. 20. The shield cup portion of the main breach had a brittle, intergranular appearance: both etched. $50 \mathrm{X}$. 


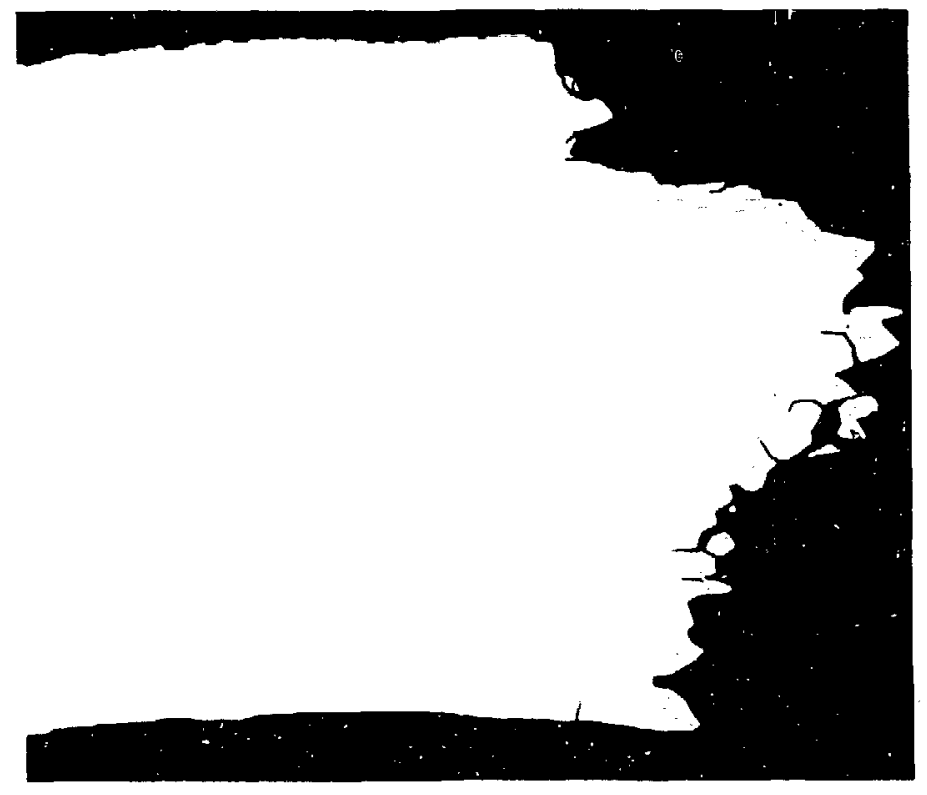

(a)

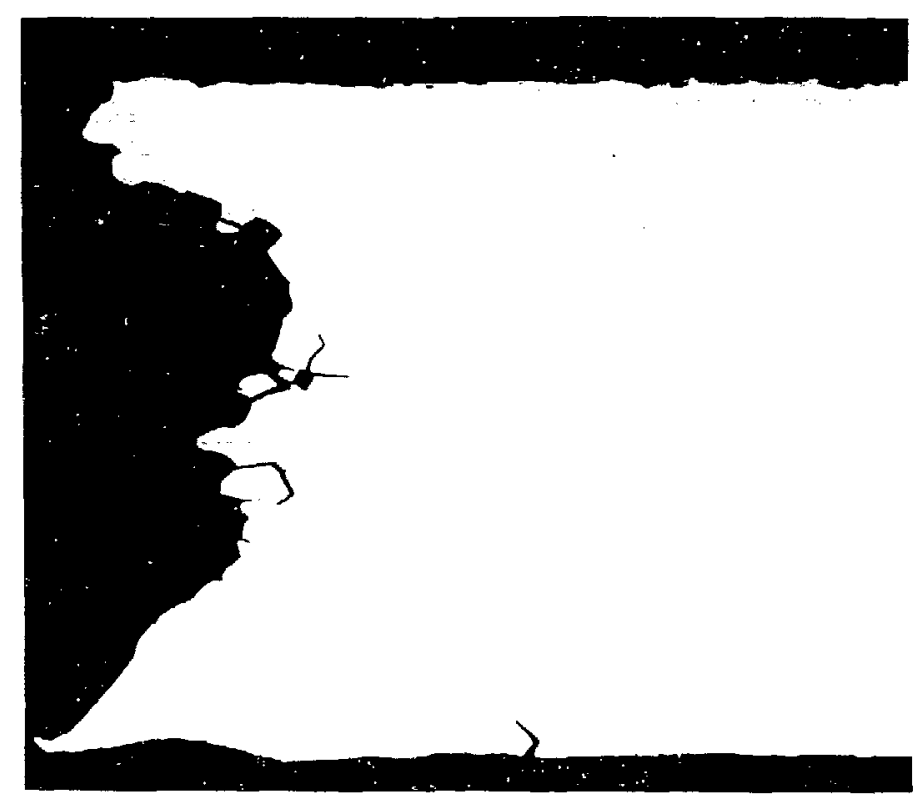

(b)

Fig. 21. There was no evidence of any iridium/aluminum reaction on the fracture surfaces within the main breach; both as polished. 50X. 


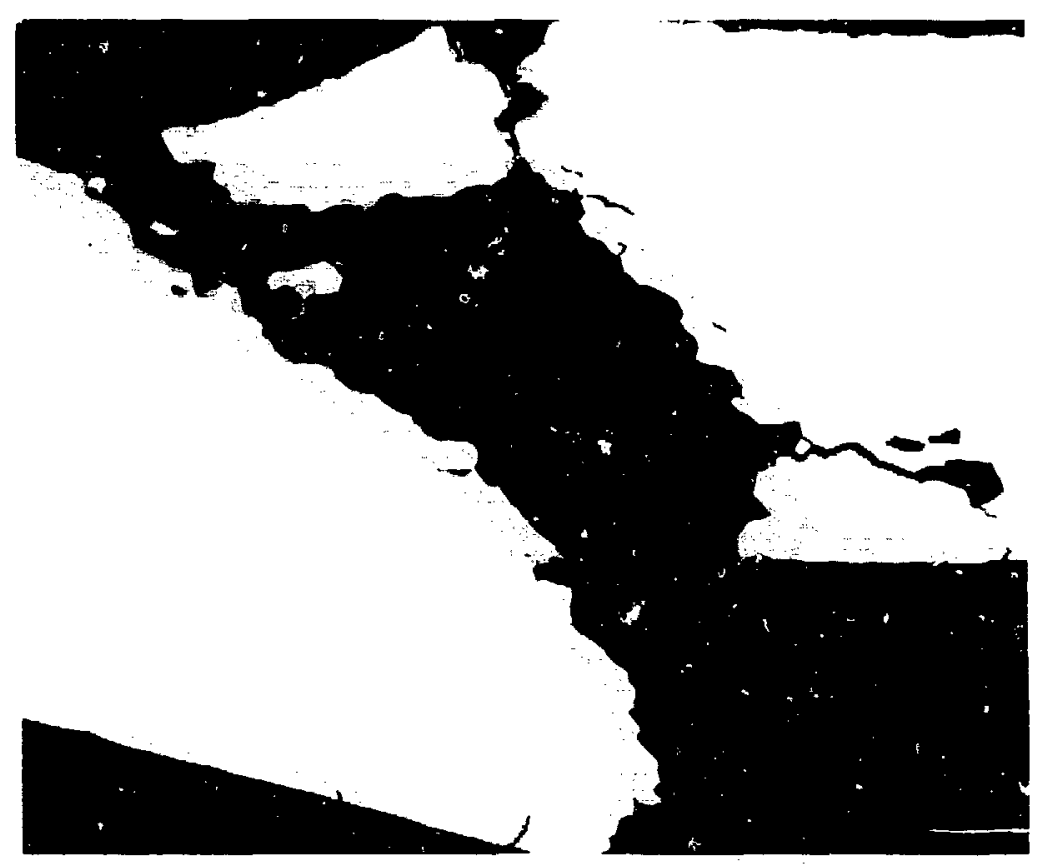

Fig. 22. A narrow crack adjacent to the main breach (immediately to the right) was coated with a layer of an iridium/aluminum reaction product; as polished, $100 \mathrm{X}$.

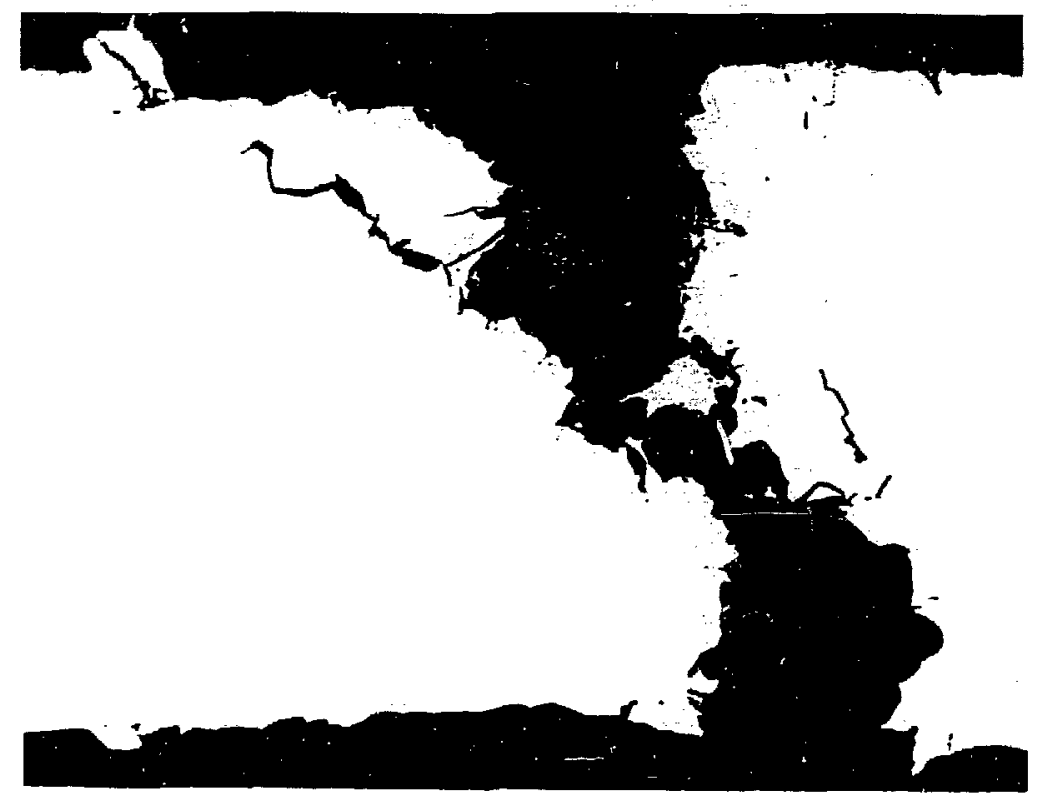

Fig. 23. A crack to the righi of the narrow breach seen in Fig. 22 was also coated with a thin deposit of an iridium/aluminum reaction product: as polished, $100 \mathrm{X}$. 


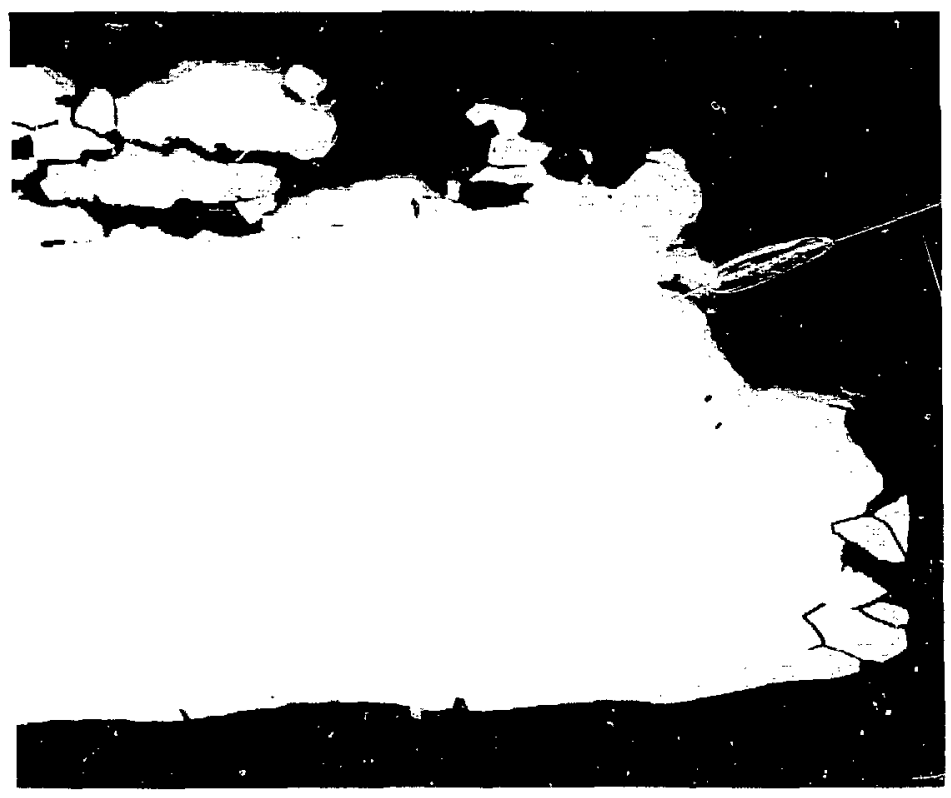

(a)

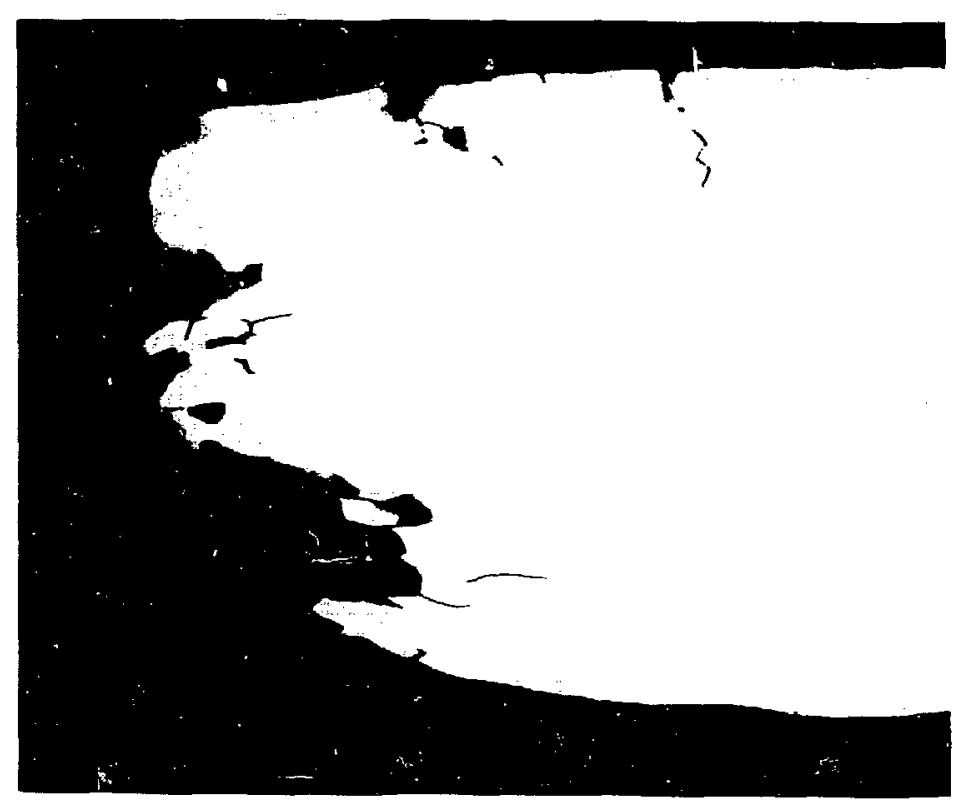

(b)

Fig. 24. A third crack. nearly $5 \mathrm{mmi}$ to the right of the main breach. contained deposits of an iridium/aluminum reaction product: both as polished. $100 \mathrm{X}$. 


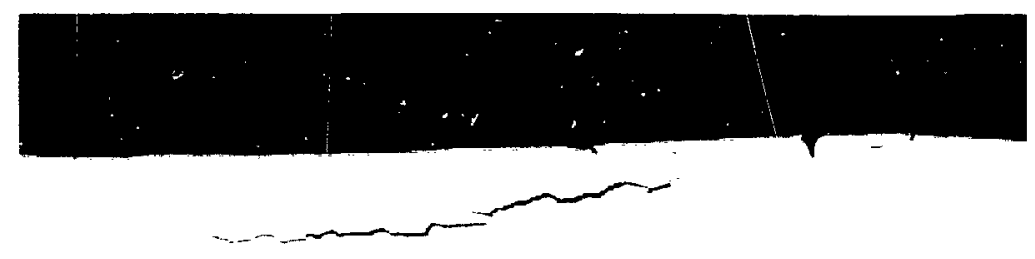

(a)
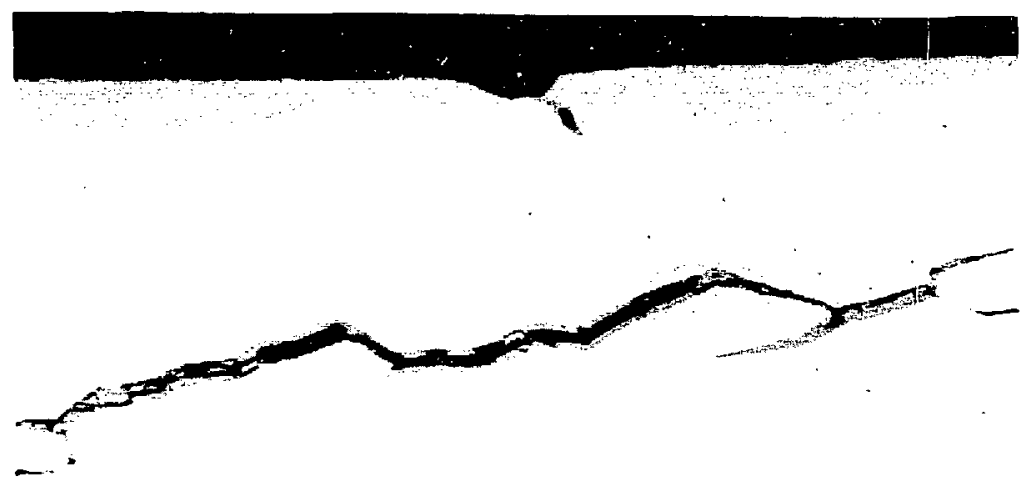

(b)

Fig. 25. Deposits of an iridium/aluminum reaction product were also observed inside an extremely narrow. delamination-type crack. (a). As polished. 50x: and (b) as polished. $250 \mathrm{X}$. 


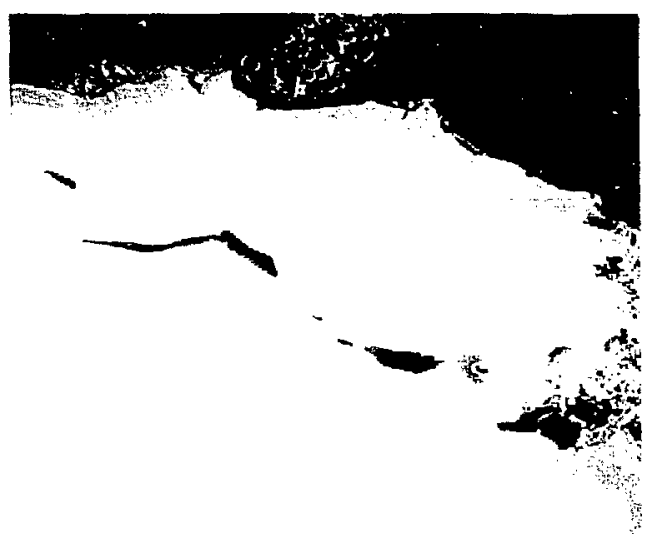

(a)

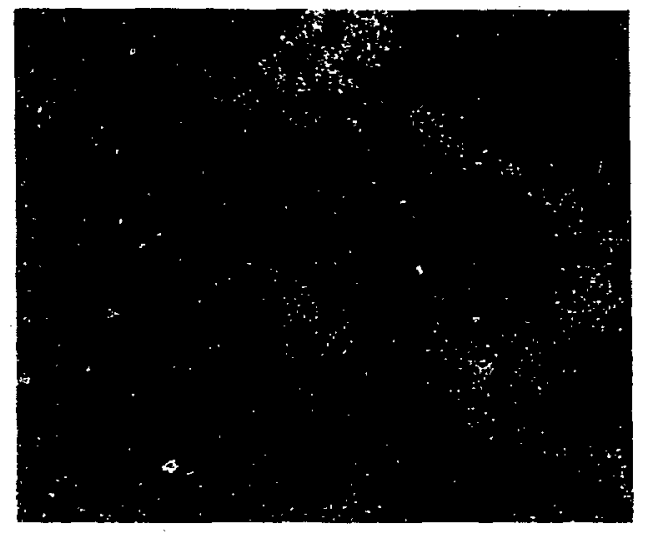

(b)

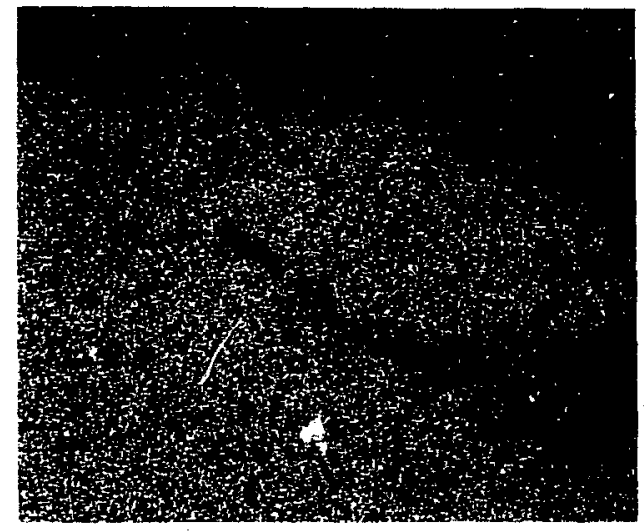

(c)

Fig. 26. EDS analysis verified that the gray deposits were a compound of aluminum and iridium. (a) Electron micrograph of a fracture surface coated with the compound, (b) dot map for aluminum of the same area, and (c) dot map for iridium. 


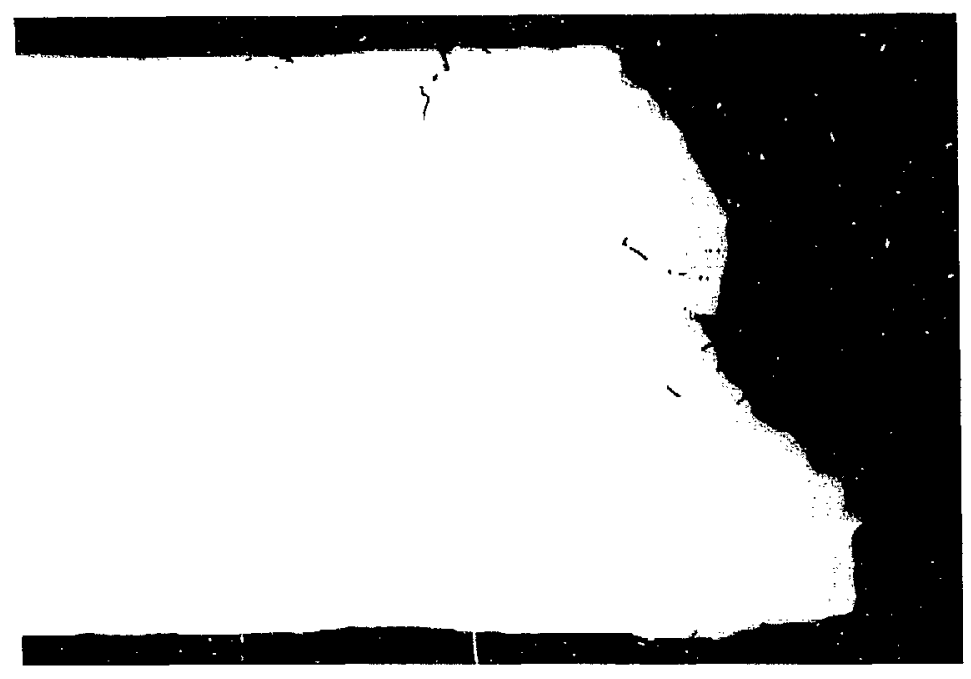

(a)

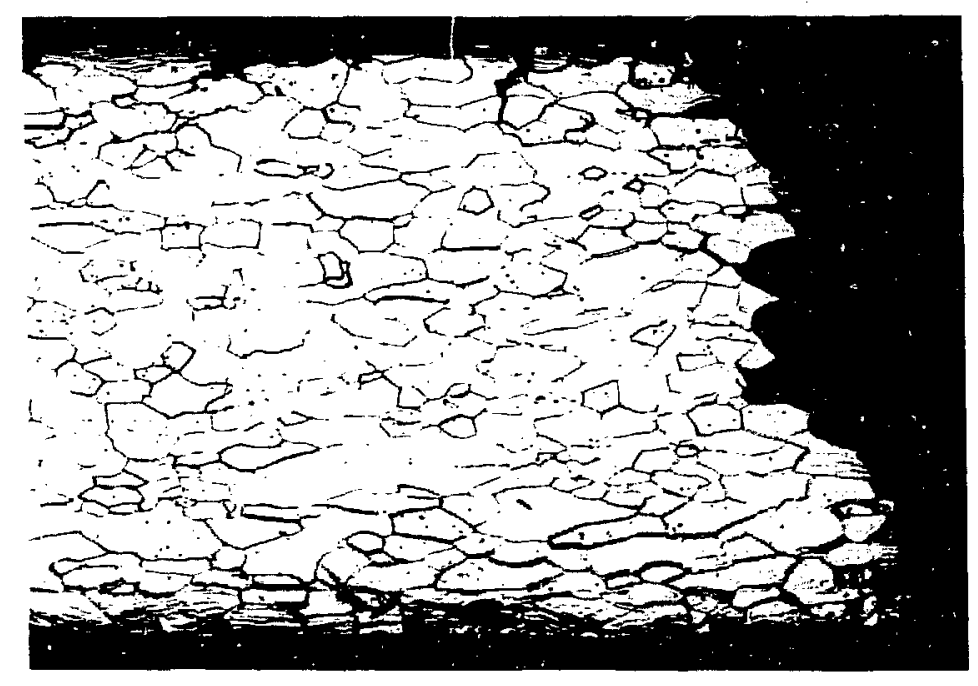

(b)

Fig. 27. The vent cup portion of the main breach contained deposits of an iridium/aluminum reaction product. (a) As polished and (b) etched: 100X. 